DIVISION OF THE HUMANITIES AND SOCIAL SCIENCES

CALIFORNIA INSTITUTE OF TECHNOLOGY

PASADENA, CALIFORNIA 91125

SPATIAL COMPETITION WITH THREE FIRMS: AN EXPERIMENTAL STUDY

Richard Collins

Katerina Sherstyuk

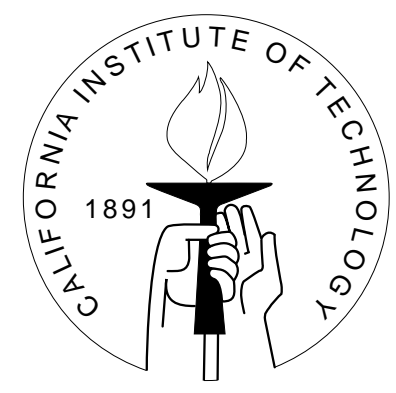

SOCIAL SCIENCE WORKING PAPER 1057

February 1999 


\title{
SPATIAL COMPETITION WITH THREE FIRMS: AN EXPERIMENTAL STUDY
}

\author{
Richard Collins and Katerina Sherstyuk* \\ Melbourne University
}

\begin{abstract}
The paper reports the results of an experimental study of the three firm location problem. We compare the subjects' behavior in the experiments with the symmetric mixed strategy Nash equilibrium calculated by Shaked (1982). Overall, the findings are consistent with the equilibrium prediction. However, the subjects' locations were significantly more dispersed than predicted by the theory. Three alternative explanations of this phenomenon - inexperience, approximate equilibrium behavior and risk aversion - are suggested and evaluated for their predictive power. Special attention is paid to risk aversion.
\end{abstract}

JEL classification codes: C9, C72, D43

\footnotetext{
* Department of Economics, Melbourne University, Parkville, Victoria 3052, Australia. Phone: (613)-9344-5316. Fax: (613)-9344-6899. E-mail: collins_richard@hotmail.com (Richard Collins), katya@cupid.ecom.unimelb.edu.au (Katerina Sherstyuk). Please direct all correspondence to the second author. We are grateful to Peter Bardsley, Kim Border, Colin Camerer, Lisa Cameron, Richard McKelvey, Tom Palfrey, seminar participants at the Australian National University, Melbourne University and Caltech, an anonymous referee and the editor for helpful discussion. We also thank Joe Rasmussen and Andrew Read for their assistance in conducting the experiments. All errors are our own.
} 


\section{Introduction}

This paper reports the results of an experimental study of the three agent location problem. Starting with the works of Hotelling (1929) and Downs (1957), models of spatial competition have been widely studied in the economics and voting literature. In economics, such models are used to study both horizontal, or geographic, competition between firms, and vertical competition, or product differentiation (for a review see Gabszewicz and Thisse, 1992). In political science, spatial voting models are used to determine equilibrium outcomes of electoral competitions (see, for example, Enelow and Hinich, 1990).

The classical model of spatial competition (Hotelling, 1929) predicts that, when two firms (or two political parties) compete for customers (voters) by choosing locations on a linear market (policy space), the only stable outcome is for both firms to locate at the center of the market. Hotelling used this result to explain the tendency for products to be very similar and political parties to become the same. He further conjectured that the tendency to cluster near the center of the market would persist in the case of more than two competing agents.

Contrary to Hotelling's conjecture, the following literature showed that in multi-agent location models, the incentive for agents to disperse is strong (see, for example, Cox, 1990). In the case of three firms, no pure strategy location equilibrium exists, as was first noted by Lerner and Singer (1937) and formally shown by Eaton and Lip sey (1975). Shaked (1982) characterizes the symmetric mixed strategy Nash equilibrium for the case of three firms and uniform distribution of buyers. He finds that the only symmetric Nash equilibrium is for each firm to locate randomly with equal probability at each point in the middle two quartiles of the market. ${ }^{1}$ Osborne (1993) shows that if there are more than two political parties who choose

\footnotetext{
1 Osborne and Pitchik (1986) find other (asymmetric) mixed strategy equilibria for this case, and further characterize symmetric location equilibria for arbitary distributions of consumers along the market spectrum and arbitrary numbers of firms. De Palma, Ginsburgh and Thisse (1987) show that when there is uncertainty about consumers' tastes, equilibrium locations in the three firm problem may be both concentrated and dispersed. In the political theory literature, Palfrey (1984) shows that in a two-candidate election, the threat of entry by a third candidate causes the positions of the two established competitors to diverge. Cox (1987) finds that elections with
} 
their positions simultaneously, then pure strategy location equilibria fail to exist in a wide range of situations. He further notes that, in the case of mixed strategy equilibria, one aspect that may be essential for characterization of outcomes is uncertainty.

The purpose of this study is to test experimentally the theoretical breakdown of centrist tendencies in a multi agent spatial competition model. Further, we are interested in considering the effects of uncertainty on the behavior of agents when no pure strategy location equilibrium exists. As argued by Osborne and Pitchik (1986), a mixed strategy equilibrium can, under certain circumstances, be viewed as a pure strategy equilibrium in a game of incomplete information. Consideration of location models where no pure strategy equilibrium exists is therefore useful for understanding firms' or political parties' behavior in an uncertain world.

The majority of existing experimental literature on spatial competition is based on voting models and considers the behavior of both candidates and voters in a spatial context. Studies of two-candidate elections indicate that, even with limited information of candidates and voters, candidates converge to the median voter ideal point (McKelvey and Ordeshook, 1985; Collier, McKelvey, Ordeshook and Williams, 1987). McKelvey and Ordeshook (1982) also find evidence that subjects use mixed strategies in two-candidate elections set in two-issue voting space when a majority rule equilibrium does not exist. They note, however, that the theoretical properties of mixed strategy equilibria of such games are only imprecisely known. Experimental studies of spatial competition among more than two candidates are less numerous. Plott (1990) compares two- and three-candidate elections under majority rule in two-dimensional voting space. Forsythe, Myerson, Rietz and Weber (1996) consider voters' behavior in three-candidate elections in non-spatial context.

Our study is most closely related to the one by Brown-Kruse, Cronshaw and Schenk (1993), who test Hotelling's duopoly model in an experimental economic setting.

more than two candidates under plurality rule (or vote maximization for each candidate) necessarily result in noncentrist equilibria. 
They consider a repeated version of the spatial duopoly game with and without communication. Their findings support the theoretical predictions: With no communication, the subjects overwhelmingly chose to locate at the center of the market. When communication was allowed, there was a strong tendency to locate at the quartiles of the market, which corresponded to a collusive equilibrium of the repeated game.

We report the results of an experimental test of the three-agent location model analyzed by Shaked (1982). Our findings are also consistent, overall, with the theory: the subjects in the experiments did not cluster at the very center, and chose, most frequently, to locate in the central quartiles of the market. However, the location choices were more dispersed than predicted by the theory; the agents often located in the out-of-equilibrium range. Further, some players "stayed away from the center" as well as the edges; that is, they located at the very center of the market less often than around it.

We suggest three alternative hypotheses to explain the above phenomena: subjects' inexperience with the game, approximate equilibrium behavior, and risk aversion. Special attention is paid to risk aversion. It is well known that one of the reasons for the nonexistence of equilibrium with three firms is that a firm that locates close to the center may find itself trapped between the other two firms, and therefore has an incentive to move just past one of its competitors. In other words, there is a higher risk in locating near the center. A number of subjects in our experiments commented after the sessions that they chose to stay away from the center to avoid being "squeezed out" by their competitors.

We theoretically investigate effects of risk aversion on agents' location strategies. ${ }^{2}$ First, we evaluate the risk as a function of location assuming the agents adopt Shaked's equilibrium strategy, and show that this strategy profile is not an equilibrium for risk averse agents. We then numerically estimate symmetric mixed strategy location equilibria for risk averse agents. Finally, we compare these risk averse predictions with the risk neutral

\footnotetext{
2 The effects of risk aversion on agents' equilibrium behavior are well acknowledged by both theorists and experimentalists in many areas of economics, such as auction theory (see Kagel, 1995).
} 
(approximate) equilibrium predictions and evaluate whether the risk averse hypothesis has better explanatory power for the data than the risk neutral hypothesis.

In section 2, we review the theory behind the experiments and describe the experimental design. Experimental results are given in section 3. In section 4, we consider alternative explanations for differences between the theoretical prediction and experimental results. We conclude our findings in section 5.

\section{Theoretical predictions and experimental design}

\subsection{Symmetric equilibrium prediction}

Shaked (1982) considers a model of non-price spatial competition among three agents on the market represented by the line interval $[0,1]$. Under the assumptions of continuous uniform distribution of consumers along the market, unit demand by each consumer, and each consumer buying from the closest firm, Shaked shows that the unique symmetric mixed strategy Nash equilibrium is for each firm to randomize uniformly over the interval $[1 / 4,3 / 4]$. The corresponding equilibrium probability density function of location, $f(x)$, is defined in equation 1 and illustrated in figure 1.

$$
f(x)= \begin{cases}2 & \frac{1}{4} \leq x \leq \frac{3}{4} \\ 0 & \text { otherwise }\end{cases}
$$

Figure 1. Distribution of locations - the Nash Equilibrium

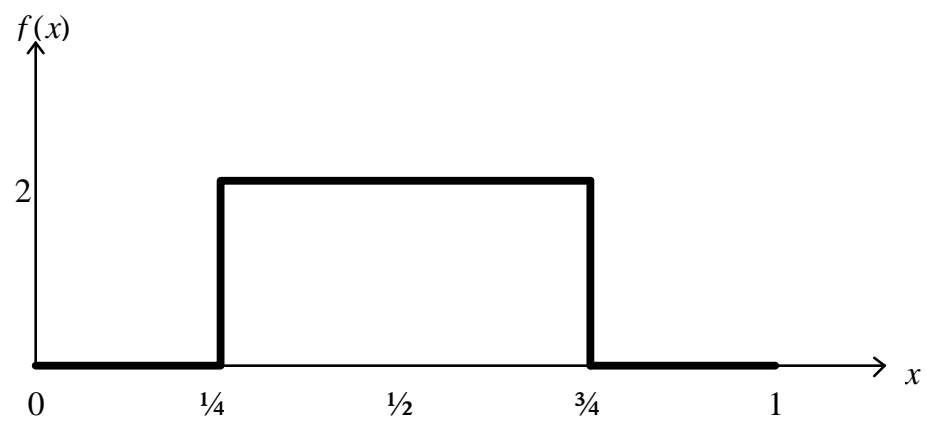




\subsection{Experimental design}

The experiments were designed to test the actual behavior of subjects in the threeagent spatial competition game against the above theoretical benchmark. The design closely follows the theoretical model of Shaked, with a number of minor modifications that simplify the experimental procedures. As in Brown-Kruse, et al. (1993), (i) the market interval was extended from $[0,1]$ to $[0,100]$, where distance was expressed to the subjects in kilometers, and (ii) the distribution of the computer simulated customers was restricted to a single customer at every integer location between 0 and 100; the subjects (firms) were restricted to choosing integer locations between 0 and 100 (inclusive). ${ }^{3}$ Each simulated customer had an inelastic demand of 10 units per period, and chose to buy from the closest firm. If firms were the same distance from a customer, the customer purchased 5 units from each. If two or more firms located at the same position, the firms shared equally the total quantity demanded by all the customers that bought from the group of firms. Firm's payoffs were proportional to the number of units sold.

\subsection{Experimental procedures}

Subjects for this experiment were recruited by advertisement from the student population of the University of Melbourne. Four experimental sessions were conducted, each containing between 9 and 18 subjects. Each session lasted for 35 periods, plus three practice period at the beginning of the session. Subjects knew that the number of periods was fixed, but were not informed of the actual last period.

At the beginning of each period, the subjects were randomly assigned to markets in groups of three. Thus, each subject's opponents changed from period to period. This randomization, the consumer demands and the payoff functions for the firms, were common knowledge. Subjects were not informed of the identity of other agents in their market at any time during the experiment.

\footnotetext{
${ }^{3}$ Numerical simulations showed that such modification of the game to a discrete market do not significantly disturb the Nash equilibrium.
} 
All experimental sessions were conducted on computer, using software developed by the authors. In each period, the subjects were asked to choose their location from the set $\{0,1,2, . ., 100\}$. The next period commenced as soon as all the participants had entered their location. At the start of a new period, each subject's computer screen showed the subject's last period location, the number of units that the subject had sold (and hence profit) and the locations of and quantity sold by the competitors in the subject's market. Subjects also could see their cumulative payoff which showed the total number of units of the product they had sold during the entire session. Additionally, a color illustration showing the location of each firm along the market in the previous period, and the associated market shares, was displayed at the start of each new period. ${ }^{4}$ At the end of the session, subjects were paid their earnings at the rate of $\$ 0.01$ per 10 units sold, plus $\$ 3$ show-up fee (Australian dollars).

\section{Experimental results}

In this section the results from the experiment are qualitatively described and statistically analyzed. We first consider whether the aggregate results from the experiment are consistent with the Nash equilibrium prediction. Further, we test for statistical differences in behavior among sessions and among individuals.

A total of 1785 observations of locations and profits were recorded during the experiment (from 51 subjects in four separate sessions with 35 choices of location for each subject). Descriptive statistics for the data pooled by sessions and across sessions are given in table 1. (Table 2A in Appendix 2 reports descriptive statistics by individual.)

\footnotetext{
${ }^{4}$ See Appendix 1 for experimental instructio ns and an illustration of subject computer screen.
} 
Table 1 Summary Statistics - Pooled Data

\begin{tabular}{lcccccccccc}
\hline & $\begin{array}{c}\text { Number of } \\
\text { subjects }\end{array}$ & $\begin{array}{c}\text { Number of } \\
\text { obser- } \\
\text { vations }\end{array}$ & Mean & Median & Mode & $\begin{array}{c}\text { First } \\
\text { quartile }\end{array}$ & $\begin{array}{c}\text { Third } \\
\text { quartile }\end{array}$ & $\begin{array}{c}\text { Standard } \\
\text { Deviation }\end{array}$ & $\begin{array}{c}\% \text { obs. } \\
\text { Outside } \\
{[25,75]}\end{array}$ & Skewness \\
\hline Nash Eq. & - & - & 50 & 50 & {$[25,75]$} & 37.5 & 62.5 & 14.43 & 0 & 0 \\
Pooled & 51 & 1785 & 50.55 & 50 & 60 & 37 & 66 & 19.08 & 18.3 & -0.01 \\
Session 1 & 12 & 420 & 50.31 & 50 & 70 & 33 & 70 & 20.91 & 25.5 & -0.09 \\
Session 2 & 9 & 315 & 52.31 & 51 & 75 & 33 & 70 & 21.07 & 23.5 & -0.11 \\
Session 3 & 18 & 630 & 50.63 & 49 & 60 & 40 & 63 & 16.16 & 11.1 & 0.04 \\
Session 4 & 12 & 420 & 49.36 & 48.5 & 35 & 35 & 65 & 19.60 & 18.1 & 0.11 \\
\hline
\end{tabular}

Figure 2 illustrates the frequency with which locations were chosen for the data pooled across all experimental sessions. (The corresponding distributions for each session are given in figure 2A, Appendix 2.) The subjects chose most frequently the 'focal point' locations that were a multiple of five (for example, $30,35,40,45$ etc.). ${ }^{5}$ To reduce the impact of the focal points on the histogram, the location choices are grouped into 21 categories (with 3 locations in the first and the last category, and 5 locations in every other category) so each category includes exactly one focal point. From figures 2 and $2 \mathrm{~A}$ and tables 1 and 2A, we conclude:

Result 1: The symmetric mixed strategy equilibrium has some explanatory power for the data. In particular, (i) no stable location choices emerged in any of the experimental sessions; and (ii) subjects chose to locate away from the edges and most frequently located in the two central quartiles of the market.

Support: Table 1 and figure 2. Figure 2 illustrates that the subjects' location choices followed a non-degenerate distribution, with the most of the probability mass falling into the central quartiles of the market. ${ }^{6}$ For the pooled data, more than 80 percent of observations

\footnotetext{
${ }^{5}$ The locations that were a multiple of five were chosen in 32.4 percent of all observations. Other locations, such as 24 , which accounted for 8.6 percent of choices, were also chosen frequently by the subjects.

${ }^{6}$ This could be the case for the pooled data even if individual subjects did not randomize their choices, but each subject chose a different location. In our experiments, however, 50 out of total of 51 subjects changed their location at least 15 times in the sequence of 35 trials; 45 subjects changed their location at least 20 times each. Hence, the subjects did not follow deterministic location rules.
} 
were within the predicted range of $[25,75]$ (see table 1). On the individual level, 40 out of 51 subjects chose locations within the central quartiles of the market 25 times or more out of 35 trials. Also, in accordance with the theoretical prediction, the mean and the median locations for all four sessions were very close to 50 . The distribution of location choices was only slightly asymmetric, as indicated by a skewness very close to zero. ${ }^{7}$

Figure 2 Distribution of Locations - Pooled Data

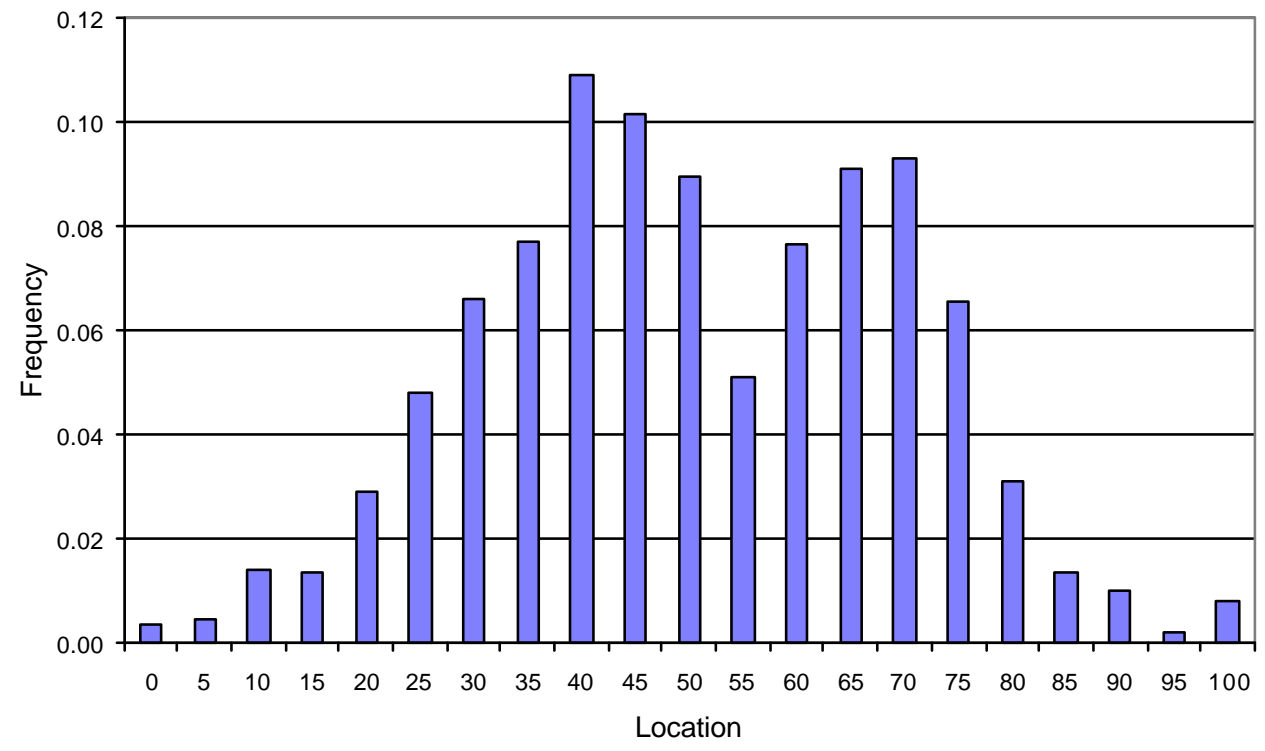

Further consideration of figure 2 indicates, however, that in contrast to the theoretical prediction, the distribution of locations in the range $[25,75]$ was not uniform. The distribution appears to be bimodal with one peak at around 40 and the other near 70. (See also the distributions from each session in figure 2A in Appendix 2.) At least to a certain degree, the subjects avoided bcations near the center of the market, as well as the edges. Statistical tests of the similarity between the data and Shaked's Nash equilibrium prediction motivate the following result.

\footnotetext{
7 The skewness for the pooled data was -0.012 with a standard error of 0.058 . The null hypothesis that the skewness is zero cannot be rejected at the $5 \%$ level with a test statistic of -0.17 compared to the critical value of 1.96. Similarly, the null hypothesis cannot be rejected for each session (the standard errors of skewness by session are $0.119,0.137,0.097$ and 0.119$)$.
} 
Result 2: The distribution of location choices was not entirely consistent with Shaked's mixed strategy equilibrium in that (i) the location choices were, overall, more dispersed than the theory predicted; and (ii) in all sessions, the distribution of location choices over the central quartiles of the market was not uniform.

Support: Tables 1 and 2. For the pooled data, the interquartile range and the standard deviation were above the theoretically predicted values (29 and 19.08, respectively, compared to the predicted values of 25 and 14.43, respectively), indicating a larger spread of locations than the equilibrium prediction. These characteristics were similar across sessions except for session 3, where the distribution was less dispersed. The differences between the observed and the theoretically predicted variances of locations are highly significant overall and for each session (the test statistics are 35.04 and 25.17, 22.44, 7.10, 19.34 for the pooled data and each session respectively, and a $5 \%$ critical value of 1.96). The results of the Kolmogorov-Smirnov test for goodness-of-fit of the data with the Nash equilibrium prediction are shown in table 2. For each of the sessions and for the pooled data, the null hypothesis of the sample being drawn from the Nash equilibrium density function is rejected at 5\% significance evel. ${ }^{8}$ Additionally, the location choices of each individual were tested for goodness-of-fit with the Nash equilibrium. The null hypothesis above was rejected for 36 out of 51 subjects at the $5 \%$ level. Thus only 15 of the subjects were using strategies consistent with the Nash equilibrium.

\footnotetext{
${ }^{8}$ The significance of the Kolmogorov-Smirnov test depends on independent draws. Since, in our case, each subject is responsible for 35 observations, one may question whether this is a reasonable assumption. To allow the reader to judge whether the significance levels are reasonable, we report the minimal $N$ that would lead to significance in each case. Also note that under the hypothesis that the subjects are using the equilibrium mixed strategies, all draws should be independent for each subject and across subjects. The Kolmogorov-Smirnov test was also used to test the data for the uniform distribution in the equilibrium range [25,75]. The null hypothesis of uniform distribution was rejected at $5 \%$ level for the pooled data and all sessions except session 3 .
} 
Table 2 Kolmogorov-Smirnov Test for Goodness-of-fit of Experimental Data with the

Nash Equilibrium Prediction

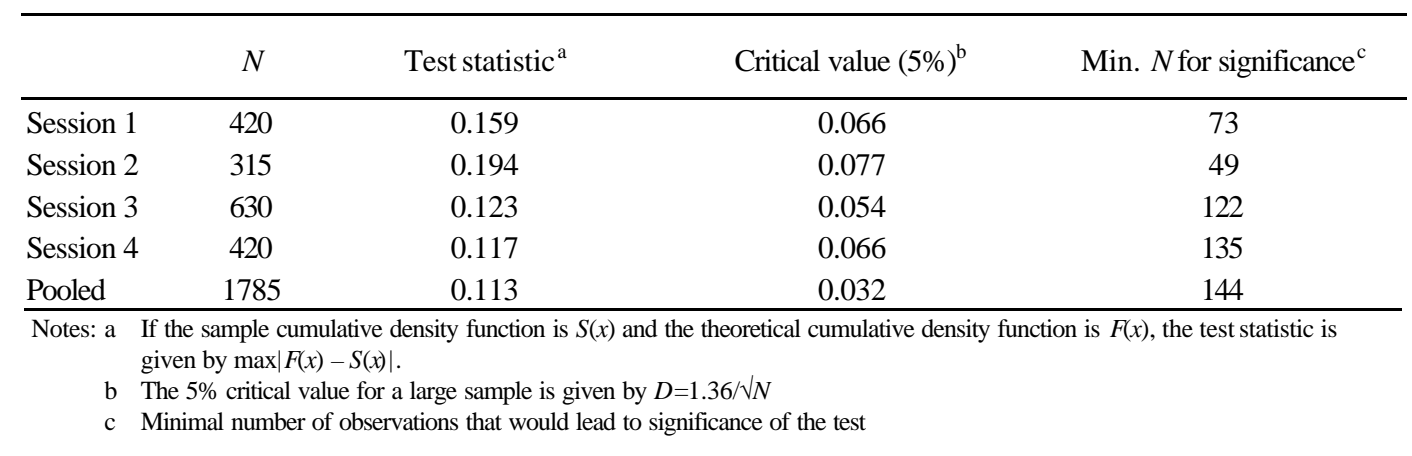

Were observed location choices consistent across sessions and individ uals? In figure 3 we illustrate the locations chosen by four individuals over the 35 periods. The figure indicates possible heterogeneity in individual location strategies (see also table $2 \mathrm{~A}$ in Appendix 2). Formal statistical tests prompt the following:

Result 3: There was significant heterogeneity in location choices across sessions and individuals. However, in each session overall and for the majority of subjects, locations were symmetric around the center of the market.

Support: The null hypothesis of no differences across the four sessions cannot be rejected at the 5\% level using the Kruskal-Wallis test (with a test statistic of 4.622 and a critical value of 7.815). This indicates that all sessions had the same median at the center of the market. However, the null is rejected at the 5\% level according to the chi squared test (with a test statistic of 249.69 and a critical value of 51.00) which detects differences in any distribution characteristics. ${ }^{9}$ On the individual level, the Kruskal-Wallis test strongly rejects the null hypothesis of no differences in individual distributions among all 51 individuals (with a test statistic of 209.75, and a 5\% critical value of 67.50). This null hypothesis cannot be rejected at the $1 \%$ significance level for a smaller sub-sample of 34 individuals (with a $p$-value of 
0.038), and cannot be rejected at a much higher significance level for yet a smaller subsample of 27 individuals (with a $p$-value of 0.971). Table 2A in Appendix 2 shows that for 37 out of 51 subjects, skewness was insignificantly different from zero at the $5 \%$ level indicating the symmetry of their location choices.

Figure 3 Four Examples of Strategies Employed
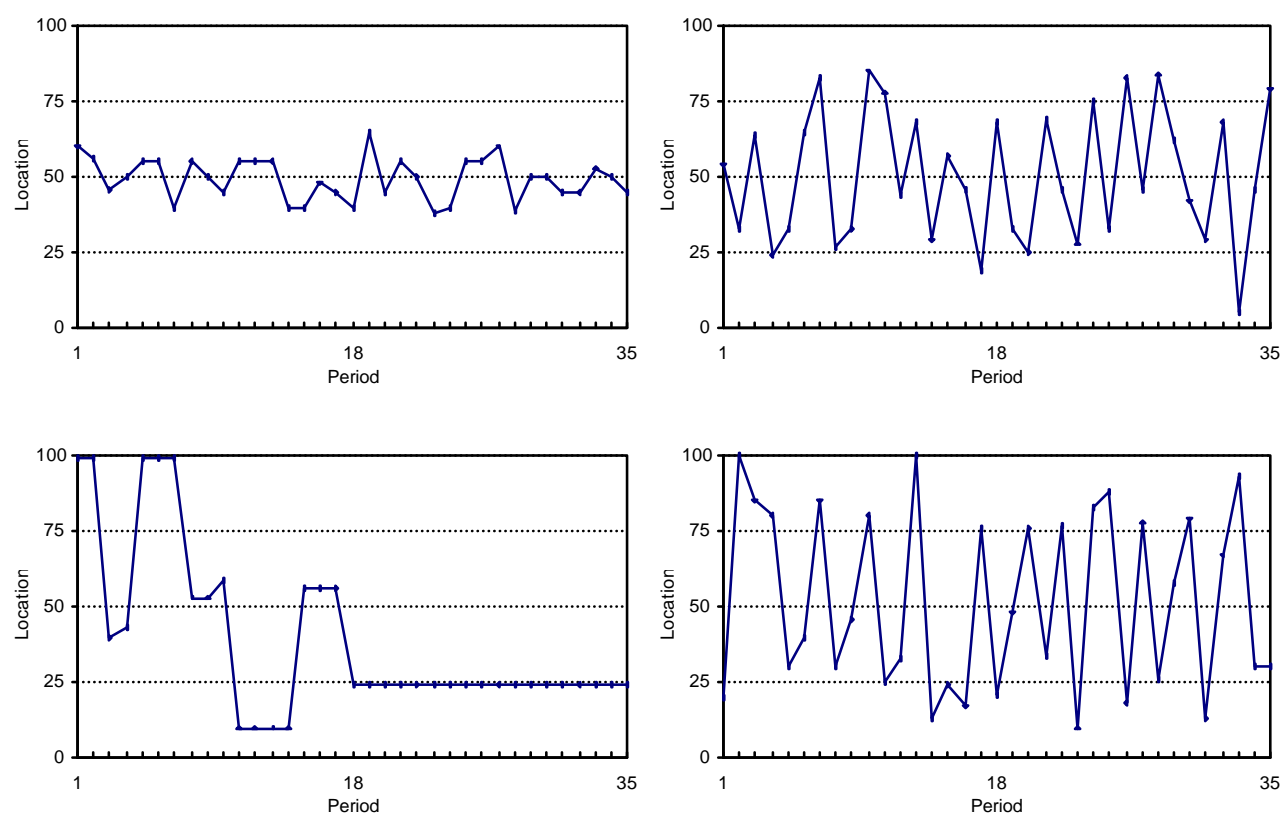

Let us summarize our findings at this stage. Although the behavior of the subjects was fairly heterogeneous on the individual level, we find that, overall, Shaked's Nash equilibrium prediction has some explanatory power over the data. In each experimental session, location choices were symmetric around the center of the market and the subjects chose, most frequently, to locate in the central quartiles. Yet we reject the hypothesis that the data is consistent with the Nash equilibrium prediction, both for the majority of the subjects and on the aggregate level. In the next section, we investigate possible reasons for differences between the theoretical predictions and the experimental results.

\footnotetext{
${ }^{9}$ For the chi-square test, the locations were pooled into categories $0-22,23-27,28-32, \ldots, 73-77$, 78-100, i.e., two categories for out-of-equilibrium locations, and 11 categories in the central quartiles of the market, each containing one focal point.
} 


\section{What can explain the differences?}

Here we explore three possible explanations for the data's inconsistency with the equilibrium prediction: subjects' inexperience with the game, approximate equilibrium behavior and risk aversion. We first present the alternative hypotheses, and then compare and evaluate them in terms of their predictive power for the data. ${ }^{10}$

\subsection{Inexperience}

Out of equilibrium play could have been caused simply by subjects' inexperience with the game. In this case, if the subjects were learning to play the Nash equilibrium as the game progressed, the number of out of equilibrium locations should fall with time. Table 3 displays proportions of such out of equilibrium locations in the first and last fifteen periods of the experiments.

Table 3. Proportion of Observations outside the Equilibrium Range

\begin{tabular}{lcccc}
\hline & \multicolumn{2}{c}{ Locations $<25$} & \multicolumn{2}{c}{ Locations $>75$} \\
& Observations & Proportion & Observations & Proportion \\
\hline All periods & 171 & 0.096 & 156 & 0.087 \\
First 15 periods & 73 & 0.095 & 66 & 0.086 \\
Last 15 periods & 78 & 0.102 & 70 & 0.092 \\
First 15 and last 15 periods & 151 & 0.099 & 136 & 0.089 \\
\hline
\end{tabular}

It is evident from the table that the number of locations in the extreme quartiles of the market did not decrease towards the end of the experiment. According to the two-tailed test for differences in two proportions (see, for example, Hamburg and Young, 1994, pp. 339340), the null hypothesis that the proportion of locations outside the equilibrium range was

\footnotetext{
${ }^{10}$ The list of explanations we offer is by no means exhaustive. Other phenomena, such as asymmetric equilibrium play, or agents' bounded rationality, may be important. Given results 1 and 3, asymmetric equilibria are not considered. We tested a simple model of boundedly rational behavior in which an agent's decision to change his or her location depended on the profit earned in the last period. However, the model possessed little explanatory power and was dismissed.
} 
the same in the first 15 periods and the last 15 periods cannot be rejected at the $5 \%$ confidence level. ${ }^{11}$ Hence, we conclude the following:

Result 4: The differences between the behavior observed and the equilibrium prediction cannot be explained solely by subjects' lack of experience with the game. The number of out-of-equilibrium locations did not decrease with time.

\subsection{Approximate equilibrium behavior}

If difference in expected payoffs between playing the equilibrium strategy and some other strategy were relatively small, and individuals did not fully optimize, they may have played any such "almost-optimal" strategy. ${ }^{12}$ Then the notion of approximate (epsilon) equilibrium may be more appropriate to explain the observed behavior than the exact equilibrium. Formally, a player's location strategy is a probability distribution over locations, represented by $p=\left(p_{0}, . ., p_{100}\right)$. Let $U^{i}\left(p^{i} ; p^{j}, p^{k}\right)$ denote the expected utility of player $i$ from playing strategy $p^{i}$ given that the opponents $j$ and $k$ play strategies $p^{j}$ and $p^{k}$ respectively. We will say that a strategy profile $\left(p^{*}, p^{*}, p^{*}\right)$, where $p^{*}=\left(p_{0}^{*}, . ., p_{100}^{*}\right)$, constitutes a symmetric $\varepsilon$-equilibrium if $U^{i}\left(q ; p^{*}, p^{*}\right) \leq(1+\varepsilon) U^{i}\left(p^{*} ; p^{*}, p^{*}\right)$ for any other strategy $q$, and any player $i$. That is, no other strategy gives $i$ an increase of utility higher than $\varepsilon$ percent relative to the $\varepsilon^{\text {-equilibrium strategy. }{ }^{13}}$

We evaluate the approximate equilibrium behavior hypothesis by comparing the experimental data with numerically evaluated symmetric $\varepsilon$-equilibria (approximate equilibria)

\footnotetext{
${ }^{11}$ There were no significant decreases in the number of out of equilibrium locations in any of the four sessions. In fact, in session 1, the number of out of equilibrium locations increased from $16.1 \%$ in the first 15 periods to $34.9 \%$ in the last 15 periods of the experiment. Similarly, on individual level, most subjects who chose the locations in out of equilibrium range in the first 15 periods of experiments, continued to do so in the later periods.

12 Many researchers note that flat payoffs around the equilibrium often lead to convergence only in an approximate sense. Subjects may not change their strategy if the expected gain is negligible. See, for example, Olson and Porter (1994).

13 It is more conventional to define $\varepsilon$-equilibria in terms of absolute, rather than relative, utility gains from deviations. However, defining the notion in terms of percentage gains is more convenient for our purposes since it is invariant in linear transformations of utility functions.
} 
of the game. The results are given in section 4.4 below. Before considering these results, we present the final alternative explanation of subject behavior.

\subsection{Risk aversion}

Due to the absence of pure strategy Nash equilibrium and the resulting uncertainty about other players' locations, individuals' location choices could be affected by risk aversion. Was this the case in our experiments? To answer this question, we first consider the risk of choosing each location in Shaked's model and in actual experiments. We then numerically evaluate symmetric location equilibria under risk aversion, and finally, compare the data with these numerical predictions.

Consider the risk associated with choosing each location in the market in Shaked's model by calculating the mean and variance of the players' payoffs under the Nash equilibrium. Suppose that two agents (firms) locate with equal probability at any point in the central quartiles of the market interval $[0,1]$. The average payoff, $A(z)$, and the standard deviation of payoff, $S(z)$, of the third firm as functions of its location, $z$, are given by

$$
\begin{aligned}
& A(z)= \begin{cases}\frac{1}{24}(12 z+5) & 0 \leq z<\frac{1}{4} \\
\frac{1}{3} & \frac{1}{4} \leq z \leq \frac{3}{4} \\
\frac{1}{24}(17-12 z) & \frac{3}{4}<z \leq 1\end{cases} \\
& S(z)= \begin{cases}\frac{1}{12 \sqrt{2}} & 0 \leq z<\frac{1}{4} \\
\frac{1}{12 \sqrt{2}} \sqrt{1536 z^{4}-3072 z^{3}+2016 z^{2}-480 z+37} & \frac{1}{4} \leq z \leq \frac{3}{4} \\
\frac{1}{12 \sqrt{2}} & \frac{3}{4}<z \leq 1\end{cases}
\end{aligned}
$$

(Equations 2 and 3 are derived in Appendix 3.) These two functions are plotted on the same axis in figure 4. From the figure, we can clearly see that the average payoff is maximized over the whole equilibrium range, but the standard deviation of the payoff is greatest at the center of the market. Intuitively, locating at the center is a high-risk strategy because the payoff may be very high if both opponents locate on one side of the firm, but it may be very low if one opponent locates on each side of the firm. The variability of payoffs diminishes towards the edges of the equilibrium mixing range and is minimized in the extreme quartiles 
of the market. This is because if the other two firms are playing the Nash equilibrium strategy, the only variability in the payoff of the firm in the out-of-equilibrium range is caused by the variability in the location of the closest opponent, not in the locations of both opponents.

Figure 4 Equilibrium Mean and Standard Deviation of Payoff

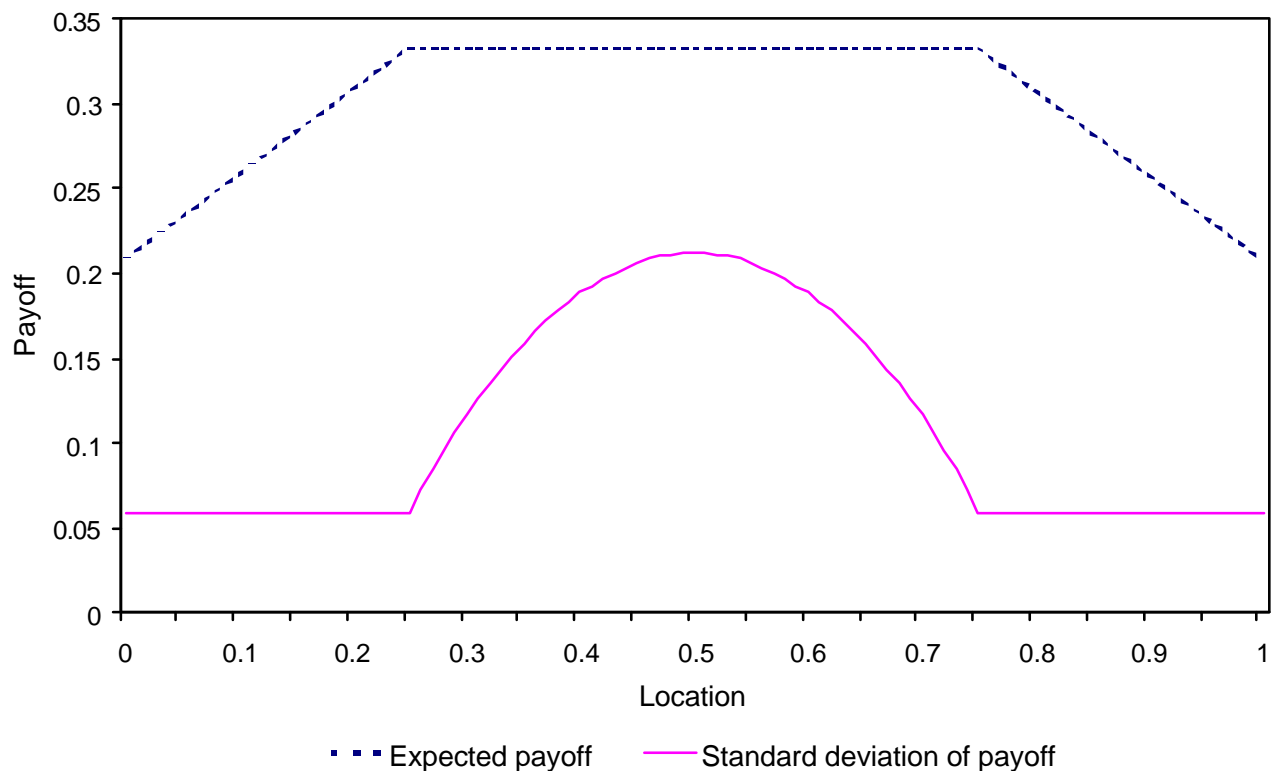


Figure 5 Mean and Standard Deviation of Profit by Location - Pooled Data

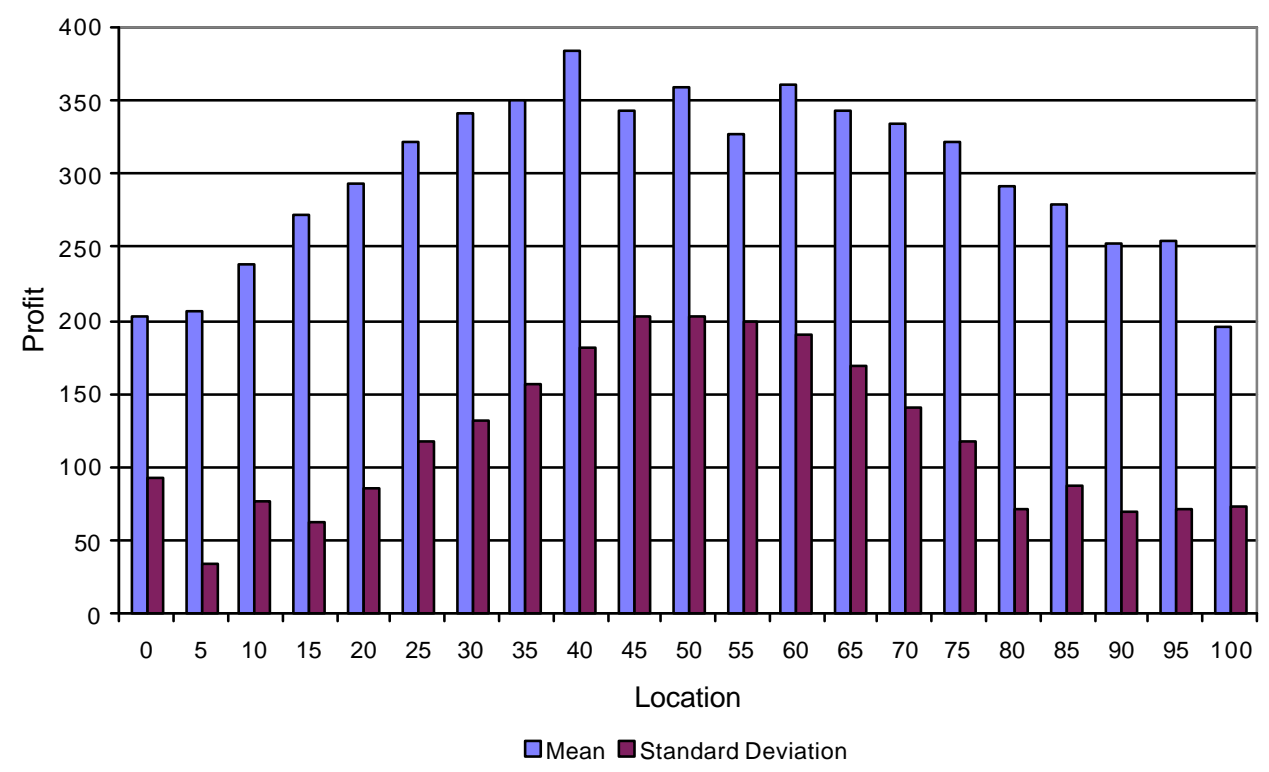

The above reasoning demonstrates that if other firms in the market are playing according to Shaked's (risk neutral) equilibrium strategy, a risk averse agent will have an incentive to locate away from the center to reduce the variance in his or her payoffs. In other words,

Proposition 1: The symmetric risk neutral location equilibrium calculated by Shaked is not an equilibrium for risk averse agents.

Let us consider the risk (in terms of payoff variance) of choosing locations in the actual experiments. Figure 5 presents the mean and the standard deviation of payoffs for each location calculated using the experimental data. From the figure it is evident that, as in the theoretical case, both the mean payoff and the standard deviation of payoff increased towards the center of the market. Moreover, the graph of average payoff appears hillshaped rather than flat in the central quartiles. This is consistent with the risk aversion hypothesis: only higher expected profits could induce risk averse agents to locate near the center of the market, where the risk was at maximum. 
It is therefore of immediate interest to evaluate location equilibria under risk aversion and consider whether these explain the data better than the risk neutral equilibrium or approximate equilibrium predictions. Intuitively, we may expect the risk-averse equilibrium strategies to put less probability weight on locating at the center to balance off the expected payoff and variance considerations. This would be consistent with the experimentally observed "dip" in the center location frequencies. Similarly, risk-aversion may cause the agents to move, with some probability, outside the central quartiles of the market, resulting in a higher degree of dispersion.

Finding an exact equilibrium of a location game requires one to solve a complicated differential equation, a problem that, in general, has not been resolved (see Osborne and Pitchik, 1986, p. 227, on the difficulty of the problem). For this reason, we use numerical methods to consider the risk-averse equilibria. This is the subject of section 4.4 below. We conclude this section by establishing that risk-averse equilibria do exist in multi-agent spatial competition games. The equilibrium existence issue is non-trivial in location games because the agents' profits (and, therefore, their utilities) are discontinuous in their locations. Fortunately, adopting the approach of Dasgupta and Maskin (1986a, 1998b), we can show the following: ${ }^{14}$

Proposition 2. Consider a spatial competition game with $N>2$ agents, where the market is represented by a non-empty compact subset $A \subset R$, and there is a continuum of consumers in the market distributed over A according to a non-atomic distribution. Suppose all agents have identical preferences given by a concave utilityof-profit function $u(\cdot)$. Then for any number of agents $N>2$, the location game has a symmetric mixed strategy equilibrium $\left(p^{*}, . ., p *\right)$, where $p^{*}$ is non-atomic on A.

\footnotetext{
14 The proof of proposition 2 is given in Appendix 4. We note that the assumption of risk aversion is crucial in establishing the equilibrium existence.
} 


\subsection{Evaluating the alternative hypotheses}

The preceding analysis shows that there may be at least two explanations of the data's inconsistency with Shaked's equilibrium prediction: risk neutral approximate equilibrium behavior and risk averse behavior. Below, we compare these explanations in terms of their predictive power for the data.

\subsubsection{The approach}

We used numerical simulations to evaluate symmetric $1 \%$ and 5\%-equilibria for the three person location games with risk neutral and risk averse agents. For the risk neutral case, the agents' utilities were identified with their market shares. For the risk averse case, the agent's utility functions were assumed to be of the form

$$
U(x)=-a e^{-R x}+b,
$$

where $x$ is the market share, $x \in[0,1], a$ and $b$ are constants normalized so that $U(0)=0$, and $U(1)=1$, and $R$ is the risk aversion parameter, taking the values $R \in\{0.5 ; 1 ; 2 ; 3 ; 4 ; 5 ; 10\} .{ }^{15}$

Due to computational constraints, locations were pooled into 15 intervals, and only discrete probability values with an increment of $1 / 28$ were considered for each location. ${ }^{16}$ Since the probability values were discrete, in the risk averse case the exact equilibrium was not always found, and the closest to the equilibrium solution in each case was sensitive to the fineness of the search grid (that is, the size of the probability increment). To avoid this problem, we evaluated, for the risk-neutral case and for each value of the risk-aversion parameter $R$, the whole sets of $1 \%$ and $5 \%$-approximate equilibria. Since there were

\footnotetext{
15 The choice of utility function and the range of risk-aversion parameters considered may seem rather arbitrary. Previous experimental studies that analyze (or control for) subjects' risk attitudes employ both constant absolute risk aversion (CARA; for example, Berg, Daley, Dickhaut and O'Brien, 1986) and constant relative risk aversion (CRRA; for example, Cox, Smith and Walker, 1988) functional forms. Our emphasis is on qualitative distinctions between risk-neutral and risk-averse cases, the distinctions that should be picked up using any class of concave utility functions. For the adopted CARA utility defined on the range of market shares (from 0 to 1 ), the given set of risk-aversion parameter covers the range from very moderate $(R=0.5)$ to rather extreme $(R=10)$ degrees of riskaversion. We also conducted a limited number of numerical evaluations using CRRA functions; the results were qualitatively similar to the CARA case.

16 The probability increments and the number of locations were chosen to guarantee the existence of the exact risk neutral equilibrium consistent with Shaked. For 15 locations, the risk neutral symmetric equilibrium is given by the
} 
typically many strategies that yielded utility levels close to the maximum, these sets contained many elements; see table 4 in the next section. Details on the numerical procedures are given

\section{in Appendix 5.}

We then used the Euclidean distance squared (EDS) measure to evaluate the similarity of the experimental data with each prediction in each approximate equilibrium set parameterized by $R$. Formally, the EDS measure between an empirical distribution of locations and a theoretically (or numerically) predicted one is given by

$$
D=\sum_{l=1}^{K}\left(p_{l}^{E}-p_{l}^{N}\right)^{2}
$$

where $l=1, \ldots, K$ indicates the location interval ( $K=15$ in our case), and $p_{l}^{E}, p_{l}^{N}$ correspond to the empirical and the numerically predicted frequencies respectively.

The empirical frequencies for the pooled data and the data for each session were compared with each element of each of the numerically evaluated $1 \%$ and $5 \%$ approximate equilibrium sets for the risk neutral and each of the risk averse cases. Then, for each empirical frequency, the best numerical prediction (i.e., the one that minimized the EDS between the predicted and the empirical frequency) was chosen. ${ }^{17}$

\subsubsection{Results}

For each $R$, the set of approximate equilibria was quite large and included a large variety of mixed strategies (probability distributions). Table 4 summarizes the numbers of symmetric mixed strategy $1 \%$ and 5\% equilibria under risk neutrality and risk aversion, out of the total of 11628 symmetric mixed strategies considered.

probability distribution $\mathrm{p}=(0,0,0,0,1 / 7,1 / 7,1 / 7,1 / 7,1 / 7,1 / 7,1 / 7,0,0,0,0)$. Thus, the feasible probability increments are of the form $(1 / 7 \mathrm{k}), \mathrm{k}=1,2, \ldots$.

17 More elaborate measures of closeness between the predicted probability distributions and the observed outcomes, such as the quadratic scoring rule (Selten, 1998), may be used to discriminate among alternative behavioral models. Such measures are particularly useful if individual strategies are considered and learning is incorporated in the model. In our case, learning is not considered beyond the scope of section 4.1. Further, since not all agents used symmetric strategies, all equilibria, not just symmetric ones, would have to be studied for the analysis of individual strategies. For the purpose of tractability, we restrict our analysis to symmetric equilibrium predictions, and compare them with the data pooled by sessions, and overall. It then suffices to use the Euclidean distance measure. 
Table 4. The number of approximate equilibria in the $1 \%$ and $5 \%$ equilibrium range.

Total number of symmetric mixed strategies considered: 11628.

\begin{tabular}{|c|c|ccccccc|}
\hline & Risk & \multicolumn{7}{|c|}{ Risk averse } \\
$\varepsilon$ & Neutral & $\mathrm{R}=0.5$ & $\mathrm{R}=1$ & $\mathrm{R}=2$ & $\mathrm{R}=3$ & $\mathrm{R}=4$ & $\mathrm{R}=5$ & $\mathrm{R}=10$ \\
\hline $1 \%$ & 11 & 24 & 50 & 118 & 212 & 306 & 461 & 2213 \\
$5 \%$ & 937 & 1421 & 1998 & 3220 & 4564 & 5894 & 7095 & 11138 \\
\hline
\end{tabular}

The table indicates that the number of approximate equilibria increases dramatically with the degree of risk aversion. This can be explained as follows. As an individual becomes more risk averse, strategies with lower expected payoff and lower risk become as attractive as strategies with higher expected payoff and higher risk. The number of such low payoff strategies i large; in the limit, a very risk averse individual attains a high utility from any strategy which yields positive payoffs, and is therefore indifferent among almost all strategies.

The above implies that almost any behavior can be explained by a large enough degree of risk aversion (thus, the set of 5\%-equilibria included 1421 strategies for the risk neutral case, and 11138 strategies for the case $R=10$; see table 4 ). This creates a potential bias in favor of the risk-averse hypothesis. We address this problem by evaluating the data against two level sets of approximate equilibria (1\% and 5\% equilibrium sets), and by checking whether the qualitative evaluations of risk attitudes are consistent across the two sets.

The results of evaluating the experimental data against the risk neutral and risk averse approximate equilibrium predictions are given in table 5. The table lists, for each approximate equilibrium set, the EDS values between the best (EDS-minimizing) predictions within the set, and the empirical distributions for each session and for the pooled data. ${ }^{18}$ Consideration of table 5 prompts result 5 .

\footnotetext{
${ }^{18}$ Observe that, at least for the sets of $1 \%$ equilibria, the numerical predictions that minimize EDS globally (across the sets parameterized by degrees of risk-aversion) are not always the element of the largest $(R=10)$ set. This shows that the above-mentioned bias in favor of risk aversion is not too large to prevent us from discriminating among different risk attitudes.
} 
Result 5: The risk-averse approximate equilibrium hypothesis explains the data better than the risk neutral hypothesis for all but one experimental session, and for the pooled data.

Support: Table 5. Within the $1 \%$ equilibrium set, for the pooled data and for all sessions except for session 3, the best risk averse predictions have the higher explanatory power for the data, in terms of EDS, than the best risk ne utral predictions. For session 3, the EDS is the lowest for the $1 \%$-equilibrium risk neutral prediction. Within the $5 \%$ equilibrium set, the best risk averse predictions explain the data at least as well as the best risk neutral predictions in all cases. For session 3, the risk neutral and risk averse hypotheses have the same explanatory power for the data within the $5 \%$ equilibrium set. 
Table 5. EDS values for the best $1 \%$ and $5 \%$ equilibrium predictions under risk

neutrality and risk aversion. Asterisks indicate minimal values.

\begin{tabular}{|c|c|c|c|c|c|}
\hline & Pooled data & Session 1 & Session 2 & Session 3 & Session 4 \\
\hline \multicolumn{6}{|c|}{$1 \%$ equilibrium } \\
\hline Risk neutral & 0.0088 & 0.0273 & 0.0294 & $0.0140^{*}$ & 0.0106 \\
\hline $\mathrm{R}=0.5$ & 0.0088 & 0.0273 & 0.0294 & $0.0140^{*}$ & 0.0106 \\
\hline $\mathrm{R}=1$ & 0.0121 & 0.0267 & 0.0223 & 0.0211 & 0.0104 \\
\hline $\mathrm{R}=2$ & $0.0062^{*}$ & 0.0147 & 0.0196 & 0.0226 & 0.0067 \\
\hline$R=3$ & 0.0079 & 0.0137 & 0.0125 & 0.0246 & 0.0104 \\
\hline $\mathrm{R}=4$ & 0.0078 & 0.0074 & 0.0120 & 0.0289 & 0.0118 \\
\hline $\mathrm{R}=5$ & 0.0078 & 0.0067 & 0.0077 & 0.0289 & 0.0118 \\
\hline$R=10$ & 0.0064 & $0.0032 *$ & $0.0073^{*}$ & 0.0254 & $0.0065^{*}$ \\
\hline \multicolumn{6}{|c|}{$5 \%$ equilibrium } \\
\hline Risk neutral & 0.0052 & 0.0134 & 0.0125 & $0.0098^{*}$ & 0.0065 \\
\hline $\mathrm{R}=0.5$ & 0.0052 & 0.0078 & 0.0125 & $0.0098^{*}$ & $0.0055^{*}$ \\
\hline $\mathrm{R}=1$ & $0.0047^{*}$ & 0.0078 & 0.0121 & $0.0098^{*}$ & $0.0055^{*}$ \\
\hline $\mathrm{R}=2$ & $0.0047^{*}$ & 0.0055 & 0.0077 & $0.0098 *$ & $0.0055^{*}$ \\
\hline $\mathrm{R}=3$ & $0.0047^{*}$ & $0.0032 *$ & $0.0073^{*}$ & $0.0098^{*}$ & $0.0055^{*}$ \\
\hline $\mathrm{R}=4$ & $0.0047^{*}$ & $0.0032 *$ & $0.0073^{*}$ & $0.0098^{*}$ & $0.0055^{*}$ \\
\hline $\mathrm{R}=5$ & $0.0047^{*}$ & $0.0032 *$ & $0.0073^{*}$ & $0.0098^{*}$ & $0.0055^{*}$ \\
\hline $\mathrm{R}=10$ & $0.0047 *$ & $0.0032 *$ & $0.0073 *$ & $0.0098^{*}$ & $0.0055^{*}$ \\
\hline
\end{tabular}

The best (EDS-minimizing) numerical predictions from the 5\% equilibrium set are plotted next to the empirical distributions in figure 7 (for the pooled data) and figure 8 (by session). The figures demonstrate that the sets of symmetric approximate equilibria contain a large variety of mixed strategies, including probability distributions with both "peaks" and "dips" at the center of the market. ${ }^{19}$ However, it appears that the risk-averse approximate equilibrium strategies differ from the risk neutral ones in the dispersion of location choices. The risk neutral prediction has a higher explanatory power for session 3, in which the location choices fell almost entirely into the central quartiles of the market. In all other

\footnotetext{
${ }^{19}$ However, it is interesting to note that numerical simulations revealed that different strategies within the same risk averse approximate equilibrium set result in similarly shaped expected profit and standard-deviation-of-profit functions. As anticipated (see discussion in section 4.3.2), the distributions of profit means and variances were hillshaped with the maximum at the center of the market. Approximate equilibria that had a "dip" at the center of the market were not always successful in explaining the data for two reasons: (i) Due to numerical constraints, location choices were aggregated into 15 groups, which significantly decreased the observed "dip" in the location frequencies; compare figures 2 and 7. (ii) Only symmetric equilibria were considered, whereas the "dip" in the empirical frequency was slightly asymmetric.
} 
sessions, subjects' location choices were more dispersed, and the risk neutral hypothesis was rejected (on the basis of EDS) in favor of risk aversion.

Figure 7: The 5\% Equilibrium Prediction and Actual Distribution of Location Choices for the Pooled Data

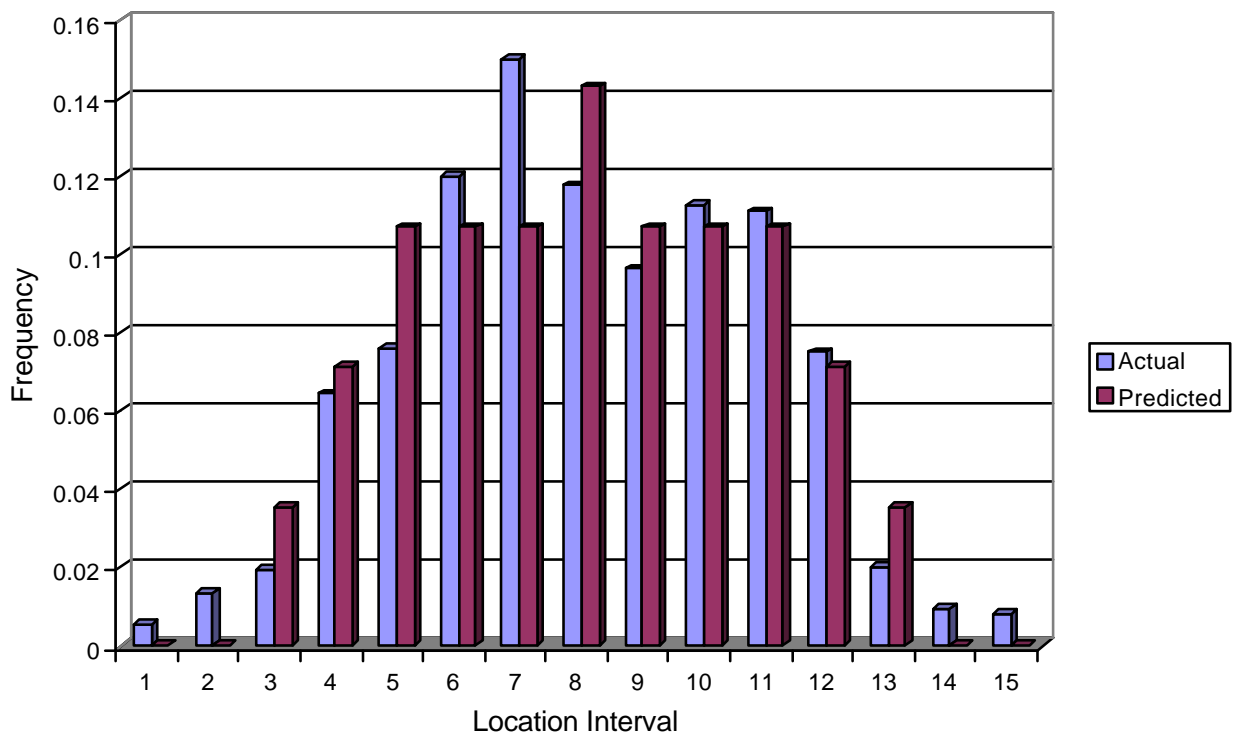


Figure 8: The Best 5\% Equilibrium Predictions and Empirical Distributions of Locations by Session

Session 1

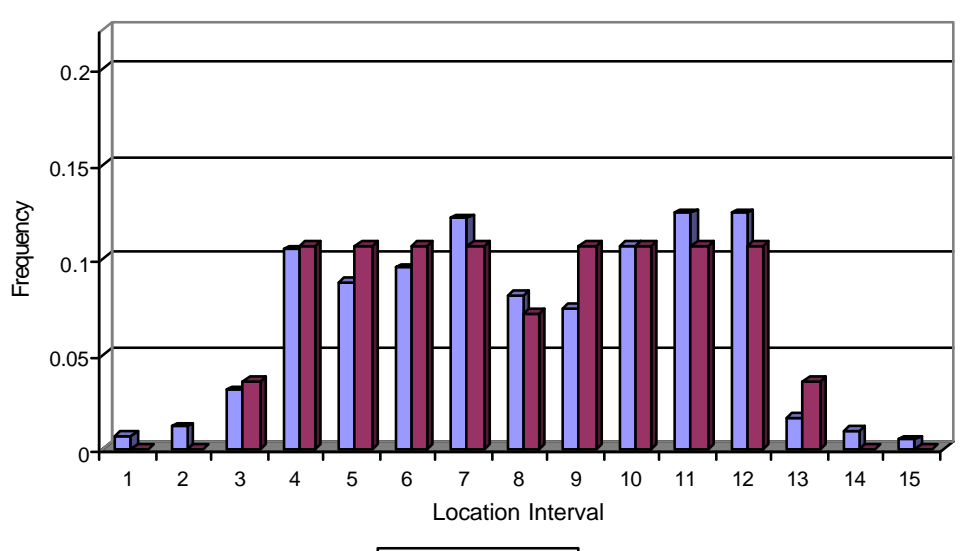

口Actual QPredicted

Session 3

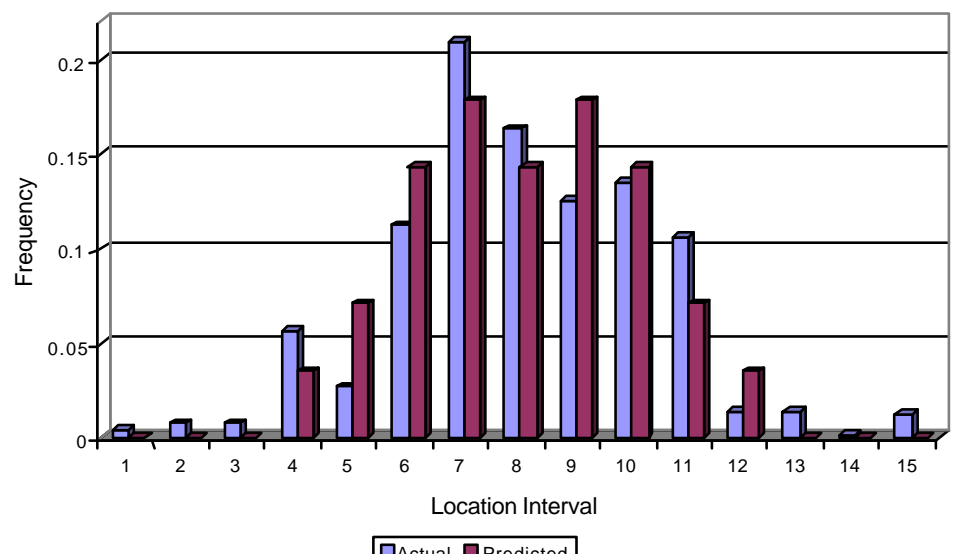

Session 2

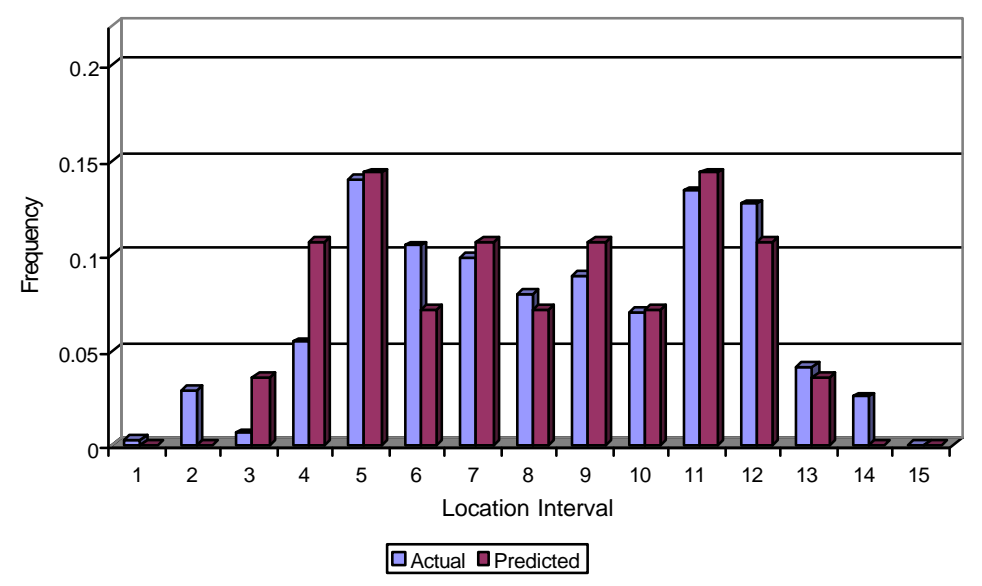

Session 4

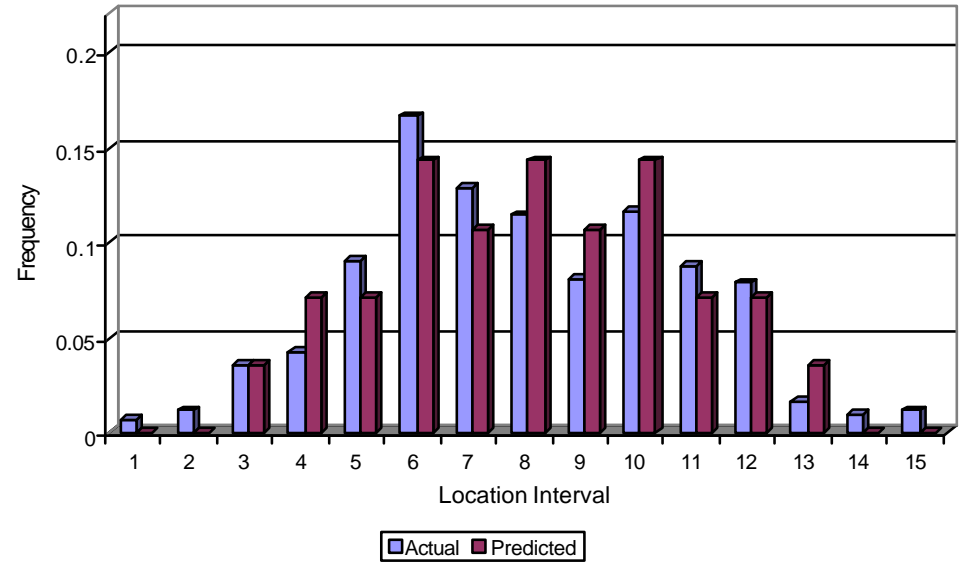


We now have sufficient evidence to conclude that the increased dispersion in subjects' location choices was caused by subjects' risk aversion together with approximate equilibrium behavior. Yet, two interesting issues remain unresolved. First, was risk aversion responsible for the subjects staying away from the very center of the market? Second, was the observed higher dispersion of choices a feature of the exact risk-averse equilibrium, or was it the result of approximate equilibrium behavior under risk aversion? A simple test allows us to answer both questions. ${ }^{20}$ For the exponential utility function with the riskaversion coefficient $R=2$ (as estimated for the pooled data; see table 5), we calculated, given the pooled empirical frequency, the expected utility of choosing each location (with the locations pooled into 21 groups around the focal points, as described in section 3). If the observed behavior constituted the exact risk-averse equilibrium, then the expected utility would be the same and at a maximum at every location in the support of the empirical frequency (probability) distribution. The results are plotted in figure 9. The figure demonstrates that the expected utility was indeed at a maximum and fairly flat in the central quartiles of the market; but it decreased outside the [25,75] range. We conclude that the agents' risk-aversion does explain why the agents located less frequently around the very center of the market. However, the higher dispersion of locations is not explained by the exact equilibrium hypothesis, and should be attributed to risk-averse approximate equilibrium behavior. ${ }^{21}$

\footnotetext{
${ }^{20} \mathrm{We}$ are grateful to Peter Bossaerts and Matthew Jackson for suggesting this approach.

${ }^{21}$ Expected utilities given the empirical frequency were also calculated for the given utility functions (CARA) with other values of $R$ in the range, and for a number of CRRA utility functions. In all cases, the expected utility was decreasing outside the central quartiles of the market. Thus, the exact equilibrium hypothesis does not explain higher dispersion in the data for a variety of concave utility functions.
} 
Figure 9. Estimated expected utility with $R=2$ for the empirical frequency

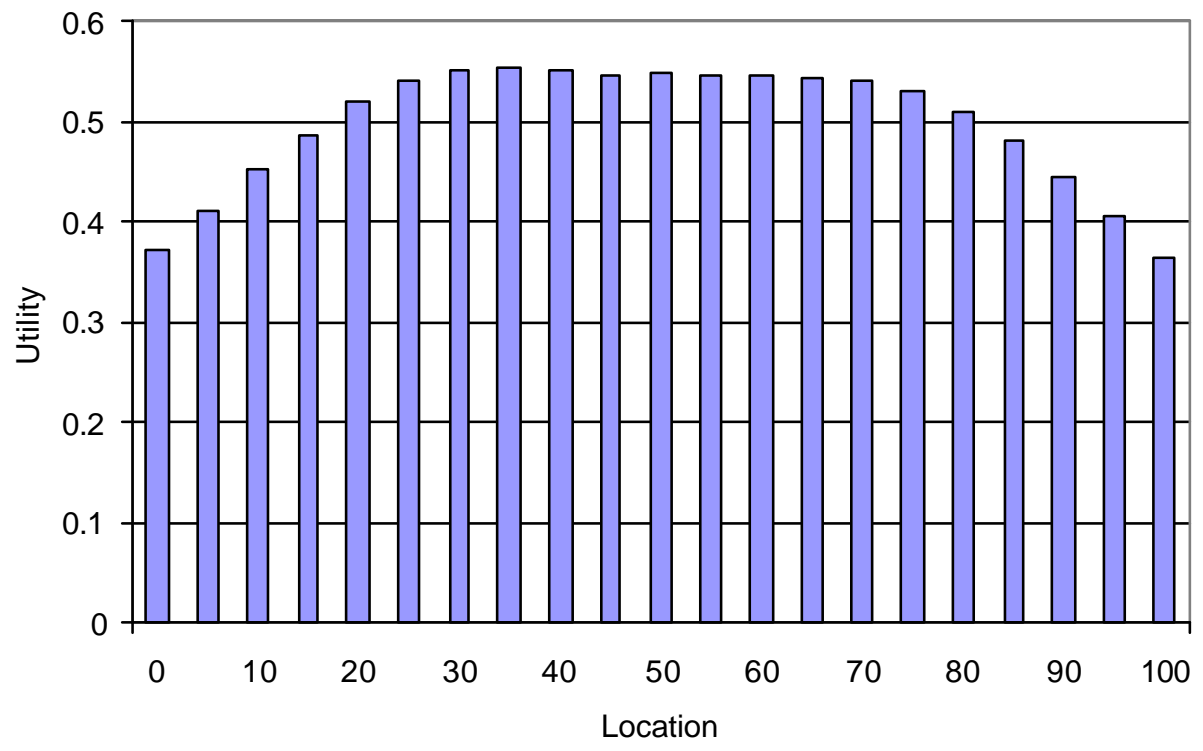

\section{Conclusions}

Our study reveals that, overall the theory has some predictive power for the analysis of multi-agent spatial competition games even if no pure strategy location equilibrium exists. In accordance with the theory, the subjects in the three-agent location experiments randomized their locations and stayed away from the edges of the market. However, we found that the subjects' behavior did not exactly correspond to Shaked's symmetric equilibrium prediction: the subjects often chose to avoid the center of the market, and the location choices were more dispersed than the theory predicted. Since such behavior persisted as the experiments progressed, it could not be attributed to subjects' inexperience with the game.

In analyzing possible causes of the observed deviations of the experimental outcomes from the theoretical predictions, we reached two important conclusions. First, the subjects' behavior in the experiments is explained better by approximate equilibria than the exact equilibrium; this is due to the presence of a large number of strategies that yield expected payoffs close to the equilibrium level. Second, risk aversion was an important 
factor that affected the subjects' behavior. Risk averse approximate equilibrium behavior induced the subjects to move away from the center of the market and to choose, with some probability, low-risk locations outside the risk neutral equilibrium range. Consequently, the location choices were more dispersed than under the risk neutral equilibrium prediction.

To the best of our knowledge, the effects of risk aversion on equilibrium outcomes have been largely ignored in the existing literature on spatial competition. This study indicates that incorporating assumptions on agents' risk attitudes into the analysis of location games may be a fruitful direction for further research. While the main body of the current literature analyzes the robustness of the centrist location tendencies in spatial competition models under isk neutrality, we find that risk aversion may be an additional factor that contributes to the breakdown of these tendencies. This conclusion has important implications both for the analysis of multi-candidate elections, and for spatial competition among firms. 


\section{Appendix 1 Instructions to Subjects}

\section{Experimental Instructions}

This research is about the economics of decision making. The instructions are simple, and if you follow them carefully and make good decisions you may earn a considerable amount of money which will be paid to you in cash at the end of the experiment.

Your payoff (or earnings) will be determined by your choices and by the choices of the other participants. All earnings will be in terms of francs. Each franc is worth dollars to you. Feel free to earn as much money as you can.

The information on your screen is private. Please do not talk to your fellow participants while the experiment is in progress.

\section{Description of the market}

You are a seller of a product who must choose a locatio $\mathrm{n}$ along a road 100 kilometers in length. However, you must share this road with two other firms selling exactly the same product. Each of the three firms along this road must choose to locate at a kilometer post between 0 and 100 (including 0 and 100).

Each firm sells the product for a fixed price of 1 franc per unit. You cannot change this price. Your cost of production is zero so that the quantity you sell is directly proportional to the profit of your firm. For example, if you sell 50 units, your profit from the sale is 50 francs.

There is a single customer for the product at every kilometer post along the road (therefore there are 101 customers). Each customer will buy 10 units of the product. As each firm's product is identical and the prices the same, each customer will purchase the product from the closest firm.

If two firms are the same distance from the customer, then the customer will buy 5 units from each firm.

If two firms locate at the same position, then each customer buys half from one firm and half from the other (the two firms each sell half the total quantity demanded). If three firms locate at the same position, then each customer buys a third from each of the firms (the three firms each sell one third of the total quantity demanded).

\section{Your instructions}

This experiment will be repeated for a fixed number of periods. In each period you must choose a single location for your firm. In each period the other two firms in your market will be selected at random from the rest of the participants.

You and the two other participants in your market will submit your chosen locations for each period using a computer. At the start of each new period the computer will show 
information about the outcomes from the last period. All that is required from you is to choose carefully the location for your firm for each period.

It is assumed that relocation is costless so you can move your firm as far as you like without penalty between periods.

At the end of each period your computer screen will show

- the location chosen by each firm in your market;

- how many units of the product your firm sold;

- the profit you earned from the sales of the product;

- how many units of the product each the other firms sold;

- the percentage of sales that each of the firms captured;

- your cumulative profit (how much you have earned during the experiment so far);

- an illustration of the market showing the location of each firm along the line and coloured bars showing the customers captured by each firm.

You may wish to record this information on the record sheet provided.

There will be a practice session of about three rounds so that you can familiarise yourself with the procedures.

\section{The computer screen}

You enter your choice of location in this box. When you click 'Submit' your choice is recorded and this box is disabled until the next period.

The market is illustrated by this dark grey rectangle.

The customers that buy from a particular firm are indicated by the coloured horizontal rectangle.

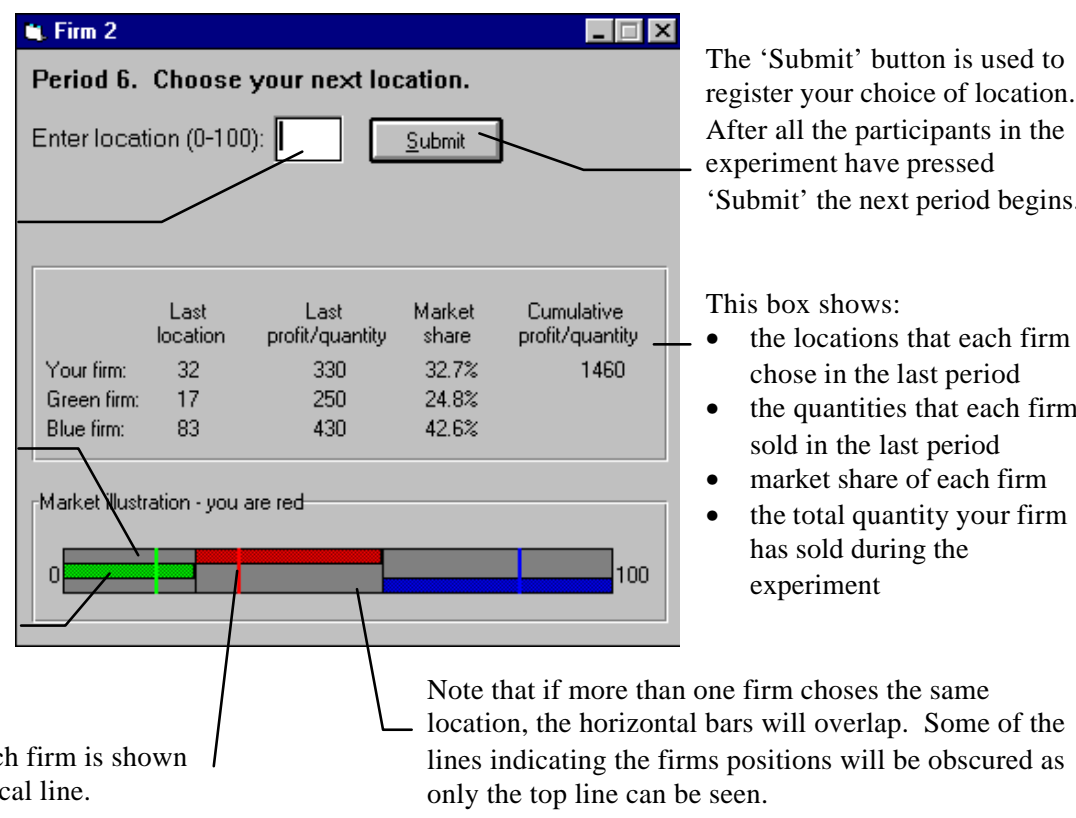

The location of each firm
by a coloured vertical line. only the top line can be seen.

In the each round, you must enter a location and press the 'Submit' button next to the location box. The computer will ask you to confirm your choice. After you (and all other participants) have pressed the 'Submit' button, the next period will begin.

When the computer records your choice, there will be a delay while all the participants' choices are collated. You will not be able to change your location during this time. When the market shares have been calculated, a yellow screen will inform you that a new period 
has commenced. You and the other two randomly selected participants in your market are now ready to choose locations for the next period.

\section{Exercises}

Firm 1 locates at $5 \mathrm{~km}$, firm 2 locates at $12 \mathrm{~km}$ and firm 3 locates at $59 \mathrm{~km}$ as in the diagram below.

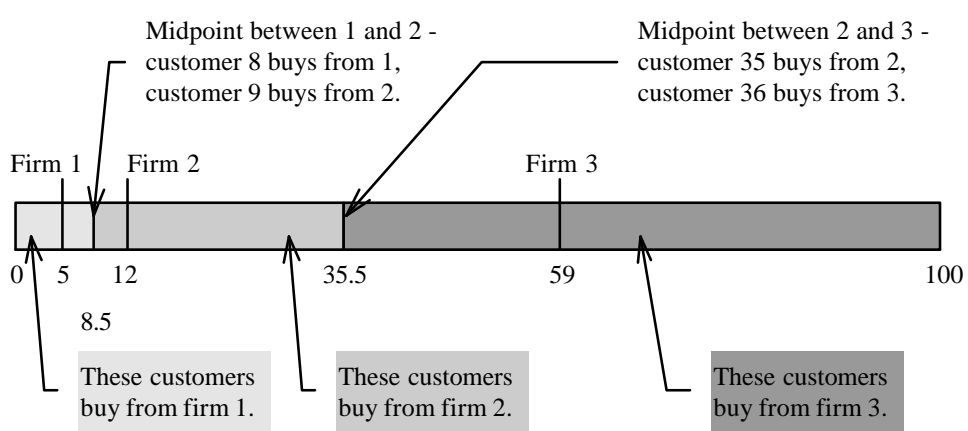

In this case firm 1 sells to all the customers between 0 and 8 and therefore sells to 9 customers. Each customer demands 10 units, so the quantity sold by firm 1 is $10 \times 9=90$ units. The selling price is 1 franc, so the profit for firm 1 is 90 francs.

Question $1 \quad$ How many customers buy from firm 2?
(a) $\quad 23$
(b) $\quad 45$
(c) 27
(d) $\quad 22$

Question $2 \quad$ Firm 3 sells to 65 customers. What is the profit for firm 3?
(a) 65 francs
(b) 550 francs
(c) 330 francs
(d) 650 francs

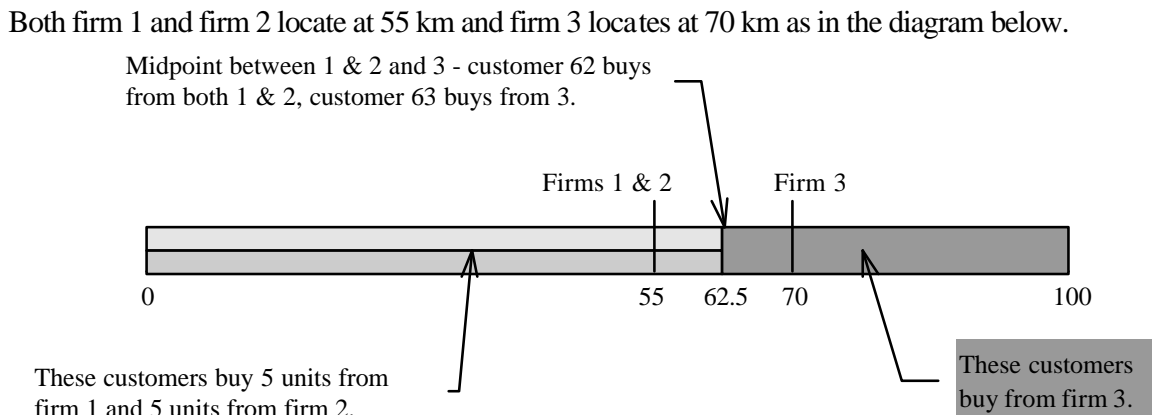

In this case firms 1 and 2 equally share the customers between 0 and 62. Firm 3 sells to all the customers between 63 and 100 .

Question $3 \quad$ How many customers buy from both firm 1 and firm 2?
(a) 63
(b) 70
(c) 19
(d) 33

Question $4 \quad$ What is the profit for firm 1?
(a) 630 francs
(b) 315 francs
(c) 230 francs
(d) 63 francs 
Are there any questions? Please raise your hand for a supervisor to check your answers and give you a consent form for you to sign.

Answers: 1.(c) 2.(d) 3.(a) 4.(b) 


\section{Appendix 2}

Table 2A Descriptive statistics of locations by individual

\begin{tabular}{|c|c|c|c|c|c|c|c|c|c|c|}
\hline & $\begin{array}{c}\text { Subject } \\
\text { DD }\end{array}$ & $\begin{array}{c}\text { Number of } \\
\text { ohs }\end{array}$ & Mean & Median & Mode & $\begin{array}{c}\text { First } \\
\text { amartile }\end{array}$ & $\begin{array}{l}\text { Third } \\
\text { awartile }\end{array}$ & Std. Dev. & $\begin{array}{c}\text { \%outside } \\
{[2575]}\end{array}$ & Skewness \\
\hline \multirow{12}{*}{ 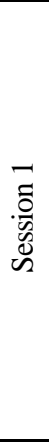 } & 1 & 35 & 45.7 & 42 & 66 & 25.5 & 67.5 & 24.1 & 37.1 & 0.25 \\
\hline & 2 & 35 & 50.5 & 50 & 30 & 30 & 73.5 & 21.9 & 25.7 & 0.03 \\
\hline & 3 & 35 & 49.4 & 50 & 55 & 45 & 55 & 6.9 & 0.0 & 0.06 \\
\hline & 4 & 35 & 56.2 & 70 & 74 & 32.5 & 72.5 & 19.3 & 2.9 & -0.47 \\
\hline & 5 & 35 & 47.7 & 39 & 34 & 28 & 71 & 22.6 & 45.7 & 0.30 \\
\hline & 6 & 35 & 43.7 & 36 & 3 & 14 & 76.5 & 33.1 & 65.7 & 0.41 \\
\hline & 7 & 35 & 42.7 & 33 & 30 & 23.5 & 67.5 & 23.1 & 42.9 & 0.60 \\
\hline & 8 & 35 & 42.9 & 48 & 19 & 19 & 65 & 23.2 & 62.9 & 0.25 \\
\hline & 9 & 35 & 58.0 & 70 & 70 & 37 & 74.5 & 18.7 & 5.7 & -0.53 \\
\hline & 10 & 35 & 57.4 & 56 & 75 & 47 & 70 & 13.0 & 5.7 & 0.18 \\
\hline & 11 & 35 & 54.4 & 54 & 63 & 40 & 66.5 & 15.2 & 11.4 & 0.16 \\
\hline & 12 & 35 & 55.2 & 60 & 65 & 42.5 & 63 & 10.2 & 0.0 & -0.63 \\
\hline \multirow{8}{*}{ 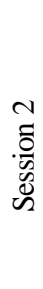 } & 13 & 35 & 56.8 & 64 & 69 & 46 & 69 & 22.7 & 25.7 & $-0.91 *$ \\
\hline & 14 & 35 & 58.7 & 71 & 70 & 33 & 75.5 & 24.5 & 37.1 & $-0.86^{*}$ \\
\hline & 15 & 35 & 47.9 & 50 & 51 & 47 & 53 & 10.5 & 5.7 & $-1.34 *$ \\
\hline & 16 & 35 & 42.1 & 39 & 37 & 37 & 43 & 9.9 & 0.0 & $1.63 *$ \\
\hline & 17 & 35 & 38.6 & 31 & 31 & 31 & 32 & 15.3 & 0.0 & $1.56^{*}$ \\
\hline & 18 & 35 & 50.4 & 46 & 33 & 33 & 68 & 22.1 & 25.7 & 0.03 \\
\hline & 19 & 35 & 48.1 & 60 & 78 & 22.5 & 73.5 & 27.9 & 57.1 & -0.03 \\
\hline & 20 & 35 & 52.9 & 54 & 50 & 44.5 & 58.5 & 13.8 & 11.4 & 0.57 \\
\hline \multirow{19}{*}{ 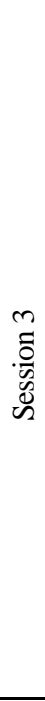 } & 21 & 35 & 75.3 & 75 & 75 & 74 & 80 & 11.7 & 48.6 & $-2.47 *$ \\
\hline & 22 & 35 & 47.0 & 48 & 40 & 39 & 59.5 & 14.6 & 8.6 & -0.34 \\
\hline & 23 & 35 & 53.7 & 56 & 45 & 45 & 63 & 10.3 & 0.0 & -0.21 \\
\hline & 24 & 35 & 49.8 & 43 & 43 & 37 & 64.5 & 15.3 & 5.7 & 0.40 \\
\hline & 25 & 35 & 50.0 & 60 & 60 & 59 & 67 & 8.7 & 0.0 & $-0.82 *$ \\
\hline & 26 & 35 & 49.1 & 50 & 22 & 24.5 & 66 & 22.3 & 37.1 & 0.24 \\
\hline & 27 & 35 & 59.6 & 68 & 69 & 47 & 69 & 14.3 & 0.0 & $-0.90 *$ \\
\hline & 28 & 35 & 50.1 & 50 & 50 & 43.5 & 59 & 10.0 & 0.0 & 0.10 \\
\hline & 29 & 35 & 39.5 & 24 & 24 & 24 & 54.5 & 28.2 & 77.1 & $1.26^{*}$ \\
\hline & 30 & 35 & 56.8 & 65 & 67 & 43 & 67 & 16.8 & 5.7 & $-1.20 *$ \\
\hline & 31 & 35 & 54.5 & 57 & 64 & 40 & 67.5 & 19.4 & 28.6 & -0.34 \\
\hline & 32 & 35 & 54.0 & 60 & 63 & 40 & 63 & 14.1 & 0.0 & -0.09 \\
\hline & 33 & 35 & 49.8 & 48 & 48 & 41 & 62.5 & 13.8 & 0.0 & 0.15 \\
\hline & 34 & 35 & 45.7 & 46 & 47 & 43 & 47 & 12.5 & 8.6 & 0.63 \\
\hline & 35 & 35 & 51.4 & 48 & 46 & 41 & 62 & 17.2 & 14.3 & 0.74 \\
\hline & 36 & 35 & 45.7 & 44 & 39 & 39 & 49 & 7.4 & 0.0 & $1.11^{*}$ \\
\hline & 37 & 35 & 50.0 & 49 & 41 & 41 & 61 & 13.5 & 2.9 & $-1.11 *$ \\
\hline & 38 & 35 & 46.5 & 44 & 44 & 40 & 47 & 8.3 & 0.0 & $1.50 *$ \\
\hline & 39 & 35 & 48.5 & 45 & 40 & 40 & 59.5 & 18.2 & 11.4 & -0.24 \\
\hline \multirow{12}{*}{ 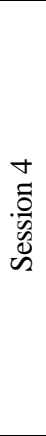 } & 40 & 35 & 49.5 & 52 & 58 & 38.5 & 64.5 & 21.8 & 25.7 & -0.22 \\
\hline & 41 & 35 & 44.1 & 35 & 35 & 32 & 50 & 17.6 & 2.9 & 0.30 \\
\hline & 42 & 35 & 54.5 & 51 & 66 & 45 & 66 & 11.1 & 0.0 & -0.40 \\
\hline & 43 & 35 & 46.8 & 38 & 37 & 36.5 & 62.5 & 15.1 & 2.9 & 0.48 \\
\hline & 44 & 35 & 40.6 & 32 & 32 & 22.5 & 63 & 23.4 & 42.9 & $0.81^{*}$ \\
\hline & 45 & 35 & 51.8 & 46 & 30 & 25.5 & 79.5 & 29.7 & 62.9 & 0.16 \\
\hline & 46 & 35 & 50.7 & 49 & 43 & 43 & 55 & 8.6 & 0.0 & 0.69 \\
\hline & 47 & 35 & 48.4 & 45 & 60 & 36 & 60 & 21.3 & 17.1 & -0.10 \\
\hline & 48 & 35 & 51.0 & 53 & 45 & 43.5 & 63.5 & 20.5 & 25.7 & -0.41 \\
\hline & 49 & 35 & 53.8 & 53 & 61 & 40.5 & 66.5 & 15.8 & 14.3 & 0.12 \\
\hline & 50 & 35 & 52.5 & 50 & 50 & 36 & 66.5 & 21.1 & 20.0 & 0.37 \\
\hline & 51 & 35 & 48.6 & 39 & 33 & 33 & 70 & 18.8 & 2.9 & 0.25 \\
\hline
\end{tabular}


Figure 2A: Distribution of Location by Session

Session 1

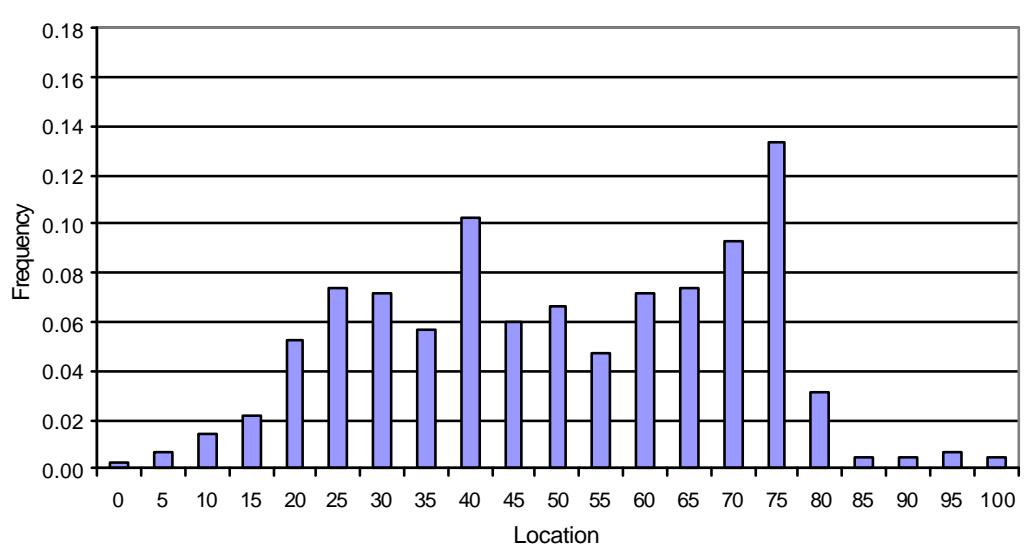

Session 3

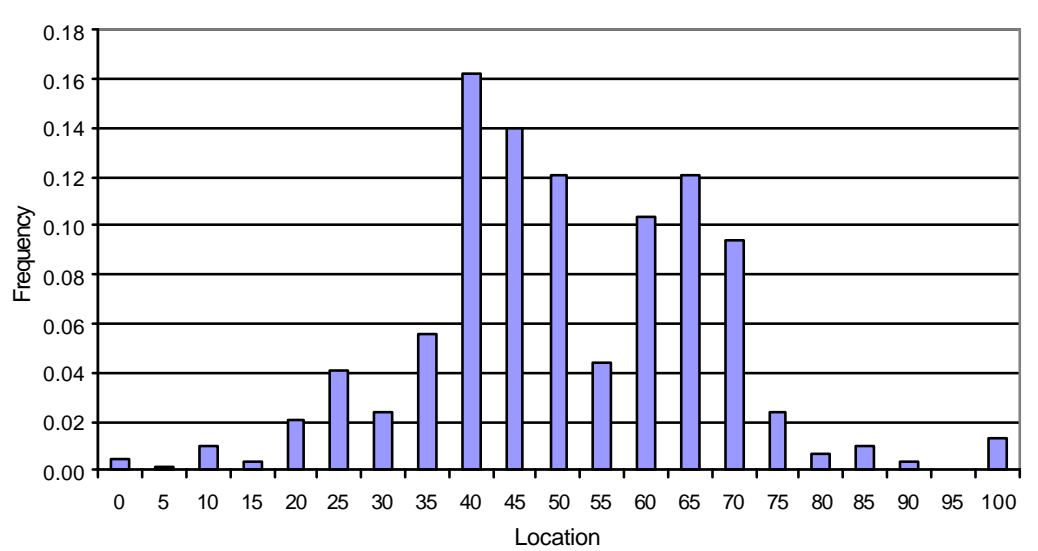

Session 2

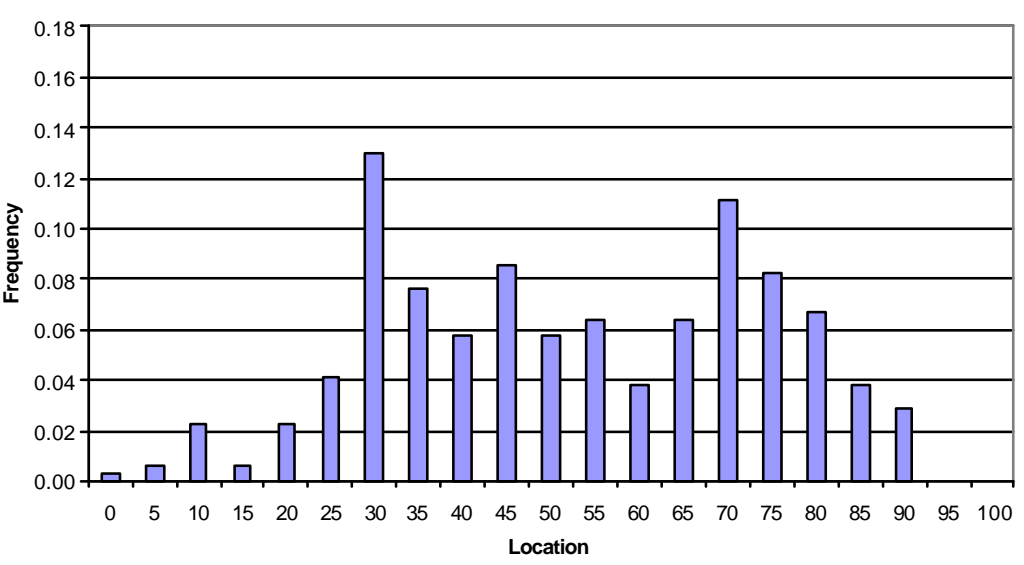

Session 4

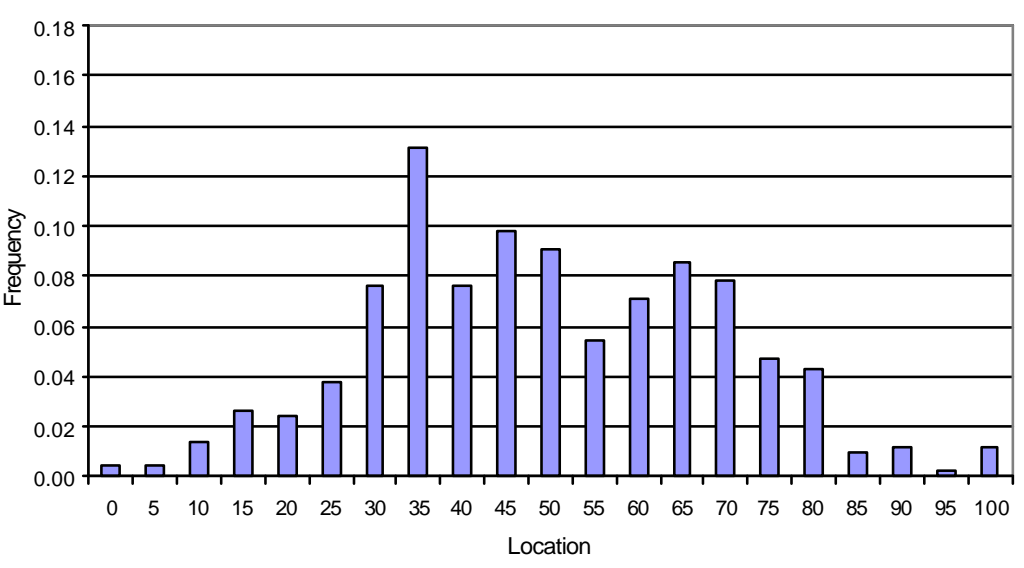




\section{Appendix 3 Derivation of expected payoff and variance of payoff as a functions of location}

Within the framework of Shaked's (1982) model, assume that firms 1 and 2 choose their locations on the linear market $[0,1]$ according to the Nash equilibrium density function given by equation (1). Let $x$ and $y$ denote locations of firms 1 and 2, respectively. We will calculate the average payoff $A(z)$ and the variance of payoff $V(z)$ of the third firm as a function of its location $z$. Let $\tilde{x}_{\min }$ and $\tilde{x}_{\max }$ denote locations of the competitor nearest to 0 and 1 , respectively, and $\tilde{\pi}(z)$ denote the payoff from locating at $\mathrm{z}$, where a tilde indicates a random variable. Further, let

$$
\begin{aligned}
& Q(x) \equiv \int_{1 / 4}^{x} f(t) d t \\
& R(x) \equiv \int_{x}^{3 / 4} f(t) d t=1-Q(x)
\end{aligned}
$$

The profit of the third firm when $z<\frac{1}{4}$ depends only on the location of the firm closest to 0 and is given by

$$
\tilde{\pi}(z)=\frac{z+\tilde{x}_{\min }}{2}
$$

The probability of the closest firm locating to the left of any point $t$ is

$$
\operatorname{Pr}\left(\tilde{x}_{\min }<t\right)=1-\operatorname{Pr}(x>t) \operatorname{Pr}(y>t)=1-\left(\frac{3}{2}-2 t\right)^{2}
$$

The expected location of the closest firm is given by

$$
E\left(\tilde{x}_{\min }\right)=\int_{1 / 4}^{3 / 4} t \frac{d}{d t} \operatorname{Pr}\left(\tilde{x}_{\min }<t\right) d t=\frac{5}{12}
$$

Thus the average payoff is

$$
A(z)=\frac{z+E\left(\tilde{x}_{\min }\right)}{2}=\frac{12 z+5}{24} \quad 0 \leq z<\frac{1}{4}
$$

The variance of the payoff when $z<\frac{1}{4}$ depends only on the variance of the location of the firm closest to 0 , which is:

$$
\operatorname{Var}\left(\tilde{x}_{\min }\right)=E\left(\tilde{x}_{\min }-E\left(\tilde{x}_{\min }\right)\right)^{2}=\int_{1 / 4}^{3 / 4}\left(t-\frac{5}{12}\right)^{2} \frac{d}{d t} \operatorname{Pr}\left(\tilde{x}_{\min }<t\right) d t=\frac{1}{72}
$$

And hence the variance of the payoff is

$$
V(z)=\operatorname{Var}\left(\frac{1}{2}\left(z+\tilde{x}_{\min }\right)\right)=\frac{1}{4} \operatorname{Var}\left(\tilde{x}_{\min }\right)=\frac{1}{288} \quad 0 \leq z<\frac{1}{4}
$$


By a similar argument, the payoff mean and variance of the third firm when $z>\frac{3}{4}$ are given by

$$
\begin{aligned}
& A(z)=1-\frac{z+E\left(\tilde{x}_{\max }\right)}{2}=\frac{17-12 z}{24} \quad \frac{3}{4}<z \leq 1 \\
& V(z)=\operatorname{Var}\left(1-\frac{1}{2}\left(z+\tilde{x}_{\max }\right)\right)=\frac{1}{4} \operatorname{Var}\left(\tilde{x}_{\max }\right)=\frac{1}{288} \quad \frac{3}{4}<z \leq 1
\end{aligned}
$$

When $\frac{1}{4} \leq z \leq \frac{3}{4}$, the expected payoff is given by

$$
\begin{aligned}
A(z)= & 2 \int_{1 / 4}^{z} f(x) Q(x)\left(1-\frac{1}{2}(z+x)\right) d x+2 \int_{1 / 4}^{z} \int_{z}^{3 / 4} f(x) f(y) \frac{1}{2}(y-x) d y d x+ \\
& +2 \int_{z}^{3 / 4} f(x) R(x) \frac{1}{2}(x+z) d x=\frac{23}{96}-\frac{3}{16}+\frac{9}{32}=\frac{1}{3}
\end{aligned}
$$

The variance of the payoff when $\frac{1}{4} \leq z \leq \frac{3}{4}$ is

$$
\begin{aligned}
V(z)= & 2 \int_{1 / 4}^{z} f(x) Q(x)\left(1-\frac{1}{2}(z+x)-\frac{1}{3}\right)^{2} d x+2 \int_{1 / 4}^{z} \int_{z}^{3 / 4} f(x) f(y)\left(\frac{1}{2}(y-x)-\frac{1}{3}\right)^{2} d y d x+ \\
& +2 \int_{z}^{3 / 4} f(x) R(x)\left(\frac{1}{2}(x+z)-\frac{1}{3}\right)^{2} d x=\frac{16}{3} z^{4}-\frac{32}{3} z^{3}+7 z^{2}-\frac{5}{3} z+\frac{37}{288}
\end{aligned}
$$

Combining (7), (10) and (12), we obtain the expected payoff from locating at $z$, as given in equation (2). Combining (9), (11) and (13) (and taking the square root of the variance), we obtain the standard deviation of the payoff at $z$, as given in (3).

\section{Appendix 4 Proof of Proposition 2}

Proof Theorem 6 in Dasgupta and Maskin (1986a) provides general conditions for the existence of a symmetric mixed strategy equilibrium in discontinuous games. Dasgupta and Maskin (1986b) further show that these conditions are satisfied for an $\mathrm{N}$-agent location game if agents are payoff-maximizers. Suppose, instead, that the agents' utilities are concave in their payoffs, i.e., the agents are risk averse. The only step in the existence proof that differs from the risk neutral case considered by Dasgupta and Maskin (1986b) is in showing that $\sum_{i=1}^{N} U^{i}(a)$, where $a=\left(a^{1}, \ldots, a^{N}\right)$ is the vector of agents locations', or pure strategies, and $U^{i}(\cdot)$ 's are individual utilities as functions of locations, is upper semicontinuous in its arguments. Here we present the proof of this property for the case of uniform distribution of consumers on [0,1], and $N=3$ agents. The proof easily extends to the general case. 
Let $x, y$ and $z$ denote locations of agents 1,2 and 3, correspondingly. By assumption, $U^{i}(x, y, z)=u\left(\pi^{i}(x, y, z)\right)$, where $\pi^{i}$ is agent $i$ 's payoff, $i=1,2,3$. Discontinuities in agents' payoffs, and, therefore, in their utility functions, occur only when two or more agents locate at the same point in the market. Hence, to prove that $\sum_{i=1}^{N} U^{i}(x, y, z)$ is upper semi-continuous in $(x, y, z)$, it is necessary and sufficient to show that, for all $x, y, z \in[0,1]$,

$$
\lim _{x \rightarrow y} \sum_{i=1}^{3} U^{i}(x, y, z) \leq \sum_{i=1}^{3} U^{i}(y, y, z)
$$

Consider the following cases.

Case 1: $y \neq z, \quad x<\min \{y, z\}$. For simplicity, assume that $y<z$. Then, given the assumption of uniform distribution of consumers on $[0,1], \pi^{3}(x, y, z)=1-\frac{z+y}{2}$ for all $x \leq y$, and hence $\left(\pi^{1}(x, y, z)+\pi^{2}(x, y, z)\right)$ is constant. Therefore, as $x \rightarrow y$, all changes in the sum of utilities are due to redistribution of profits between agents 1 and 2. By concavity of $u(\cdot)$, the sum of the utilities is maximized when $\pi^{1}(x, y, z)=\pi^{2}(x, y, z)$, which is the case when $x=y$. Thus,

$$
\begin{gathered}
\lim _{x \rightarrow y} \sum_{i=1}^{3} U^{i}(x, y, z)=\lim _{x \rightarrow y} u\left(\pi^{1}\right)+\lim _{x \rightarrow y} u\left(\pi^{2}\right)+\lim _{x \rightarrow y} u\left(\pi^{3}\right)= \\
=u(y)+u\left(\frac{z-y}{2}\right)+u\left(1-\frac{z+y}{2}\right) \leq \\
\leq 2 u\left(\frac{z+y}{2}\right)+u\left(1-\frac{z+y}{2}\right)=\sum_{i=1}^{3} U^{i}(y, y, z) .
\end{gathered}
$$

The case when $x>\max \{y, z\}$ is analogous.

Case 2: $y \neq z, \min \{y, z\}<x<\max \{y, z\}$. For simplicity, assume that $y<x<z$. (The case $z<x<y$ is analogous.) As $x \rightarrow y$, the payoffs of both agents 2 and 3 change, but there is no discontinuity in agent's 3 payoff at $x=y$. Again, by concavity of $u(\cdot)$, the sum of the utilities of agents 1 and 2 is maximized when $\pi^{1}(x, y, z)=\pi^{2}(x, y, z)$, which is the case when $x=y$. Hence, 


$$
\begin{gathered}
\lim _{x \rightarrow y} \sum_{i=1}^{3} U^{i}(x, y, z)=\lim _{x \rightarrow y} u\left(\pi^{1}\right)+\lim _{x \rightarrow y} u\left(\pi^{2}\right)+\lim _{x \rightarrow y} u\left(\pi^{3}\right)= \\
=u\left(\frac{z-y}{2}\right)+u(y)+u\left(1-\frac{z+y}{2}\right) \leq \\
\leq 2 u\left(\frac{z+y}{2}\right)+u\left(1-\frac{z+y}{2}\right)=\sum_{i=1}^{3} U^{i}(y, y, z) .
\end{gathered}
$$

The case when $y<x<z, x \rightarrow z$ is analogous.

Finally, concavity of $u(\cdot)$ implies that inequality (14) holds as $x \rightarrow y$ when $y=z$

(case 3). In fact, $\sum_{i=1}^{N} U^{i}(x, y, z)$ attains its global maximum at $x=y=z$

\section{Appendix 5 Numerical evaluations of approximate equilibria}

Approximate symmetric equilibria for the 3 agent location game we evaluated as follows. Due to computational constraints, all locations were pooled into $K$ intervals, and only discrete probability values with an increment of $1 / N$ were considered. A mixed strategy was then represented by a $K$-dimensional probability vectors $p=\left(p_{1}, . ., p_{k}\right)$, where $p_{l}$ denotes the probability of locating in interval $l$. In a symmetric equilibrium, each player adopts the same strategy $p=p *$. To find such equilibria, for every feasible strategy $p$ adopted by agents 1 and 2, the algorithm searched, over the feasible set determined by $K$ and $N$, for best response strategies $q(p)$ of player 3, i.e., the strategies that maximized his expected utility $U^{i}(q ; p, p)$. (Typically, the best responses were not unique, but they all yield ed the same utility). For each pair $(p ; q(p))$, the algorithm evaluated utility gains from using the best response strategy $q(p)$ as compared to the strategy $p$ adopted by other players:

$$
G(p)=U^{i}(q(p) ; p, p)-U^{i}(p ; p, p) .
$$

A symmetric Nash equilibrium is characterized by a strategy $p^{*}$ such that $G\left(p^{*}\right)=0$. Because the problem of finding such $p^{*}$ is non-convex in $(p ; q(p))$, we were forced to use a grid search algorithm to search for the equilibria. Due to the discreteness of the probability space, the exact symmetric equilibrium was not always found, and the closest to the equilibrium solution ( $p$ at which the gains function $G(p)$ was minimized) was very sensitive to 
the choice of the number of locations $K$, probability increments $N$, and the risk aversion parameter $R$. To avoid this problem, we evaluated the whole set of $\varepsilon$-equilibria, i.e., the set of all probability distributions $p$ for which $G(p) / U(p ; p, p) \leq \varepsilon \cdot \cdot^{22}$

In the estimations reported in section 4.4 , we set $K=15$ location intervals, $N=28$ probability increments, and $\varepsilon=1 \%$ or $\varepsilon=5 \%$. $N$ and $K$ were chosen to guarantee the existence of the exact mixed strategy risk neutral equilibrium consistent with Shaked (see footnote 16 in the main text.) Since the search was constrained to symmetric equilibria, only the probability distributions symmetric around the center of the market were considered. Further, the search was restricted to mixed strategies such that $p_{1}=p_{2}=p_{14}=p_{15}=0$. This was done for the sake of computational efficiency. In earlier trials, these constraints were not imposed, at the expense of choosing smaller $N$. The numerical predictions which best explained the empirical data (in terms of EDS; see section 4.4.1) always assigned zero probabilities to the first and last two location intervals. We conclude that these restrictions did not significantly affect the results. With all the above restrictions in place, the total of 11628 probability distributions were considered.

\section{References}

Berg, J.E., Daley, L.A., Dickhaut, J.W. and O’Brien, J.R., 1986, “Controlling Preferences for Lotteries on Units of Experimental Exchange," Quarterly Journal of Economics 101, 281-306.

Brown-Kruse, J., Cronshaw, M.B. and Schenk, D.J., 1993, "Theory and Experiments on Spatial Competition”, Economic Inquiry 31, 139-65.

Collier, K.E., McKelvey, R.D., Ordeshook, P.C. and Williams, K.C, 1987, "Retrospective Voting: An Experimental Study," Public Choice 53, 101-130.

\footnotetext{
${ }^{22}$ An alternative way to search for a symmetric equilibrium would be to define a distance function between $p$ and $q(p), v(p)=\|p-q(p)\|$, and then find $p$ at which the distance is minimized. However, due to the discreteness of the algorithm and the resulting discontinuity of $v(p)$ in $p$, such a method produced unsatisfactory results. Typically, the utility gains from adopting the best response strategy $q(p)$ as compared to the symmetric strategy $p$ that minimized $v(p)$, were substantial.
} 
Cox, Gary W., 1987, “Electoral Equilibrium under Alternative voting Institutions,” American Journal of Political Science, V. 31, 82-108.

Cox, Gary W., 1990, "Multicandidate Spatial Competition," in Advances in the Spatial Theory of Voting, edited by J.M. Enelow and M. J. Hinich. Cambridge University Press. Chapter 8, 179-198.

Cox, J., Smith, V., and Walker, J., 1988, "Theory and Individual Behavior of First-Price Auctions," Journal of Risk and Uncertainty 1, 61-99.

Dasgupta, P., and E. Maskin, 1986a, "The existence of equilibrium in Discontinuous Economic Games, I: Theory,” Review of Economic Studies 53, 1-26.

Dasgupta, P., and E. Maskin, 1986b, "The existence of equilibrium in Discontinuous Economic Games, II: Applications,” Review of Economic Studies 53, 27-41.

Downs, A., 1957, “An Economic Theory of Democracy,” Harper and Row, New York.

De Palma, A., Ginsburgh, V. and Thisse, J.-F., 1987, “On Existence of Location Equilibria in the 3-Firm Hotelling Problem", Journal of Industrial Economics 36, 245-52.

Eaton, B.C., and Lipsey, R.G., 1975, "The Principle of Minimum Differentiation Reconsidered: Some New Developments in the Theory of Spatial Competition", Review of Economic Studies 42, 27-49.

Enelow, James M., and M. J. Hinich, editors, 1990, Advances in the Spatial Theory of Voting. Cambridge University Press.

Forsyth, Robert, and T.A. Rietz, R. Myerson, and R. J. Weber, 1996, “An Experimental Study of Voting Rules and Polls in Three-Candidate Elections," International Journal of Game Theory, 25: 355-383.

Gabszewicz, Jean J., and J.-F. Thisse, 1992, "Location," in Handbook of Game Theory, edited by R.J. Aumann and S. Hart. Elsevier Science Publishers, V. 2, 281-304.

Hamburg, M. \& Young, P., 1994, Statistical Analysis for Decision Making, $6^{\text {th }}$ ed., Harcourt Brace \& Company, Fort Worth, Texas.

Hotelling, H., 1929, “Stability in Competition”, Economic Journal 39, 41-57. 
Kagel, John H., 1995, “Auctions: A Survey of Experimental Research,” in Handbook of Experimental Economics, edited by J. Kagel and A. Roth. Princeton University Press, p. $501-586$.

Lerner, A.P. and Singer, H.W., 1937, "Some Notes on Duopoly and Spatial Competition”, Journal of Political Economy 45, 145-86.

McKelvey, R.D. and Ordeshook, P.C., 1982, “Two-Candidate Elections without Majority Rule Equilibria: An Experimental Study,” Simulation and Games 13(3), 311-335.

McKelvey, R.D. and Ordeshook, P.C., 1985, "Sequential Elections with Limited Information," American Journal of Political Science 29(3), 480-512.

Olson, Mark, and David Porter, 1994, "An Experimental Examination into the Design of Decentralized Methods to solve the Assignment Problem with and without Money," Economic Theory, 4:11-40.

Osborne, Martin, and Carolyn Pitchik, 1986, "The nature of Equilibrium in a Location Model,” International Economic Review, V.27, 223-237.

Osborne, Martin, 1993, "Candidate Positioning and Entry in a Political Competition," Games and Economic Behavior, V.5, 133-151.

Palfrey, Thomas R., 1984, "Spatial Competition with Entry,” Review of Economic Studies, V. 51, 139-156.

Plott, Charles, 1991, A Comparative Analysis of Direct Democracy, Two-Candidate Elections, and Three-Candidate Elections in an Experimental Environment," in Laboratory Research in Political Economy, edited by Thomas R. Palfrey. Ann Arbor, The University of Michigan Press, 11-31.

Selten, R., 1998, “Axiomatic Characterization of the Quadratic Scoring Rule,” Experimental Economics 1, 43-62.

Shaked, A., 1982, "Existence and Computation of Mixed Strategy Nash Equilibrium for 3Firms Location Problem”, Journal of Industrial Economics 31, 93-97. 